\section{D) Check for updates}

Cite this: Mater. Adv., 2021, 2,6246

Received 10th August 2021, Accepted 12th September 2021

DOI: $10.1039 / \mathrm{d} 1 \mathrm{ma} 00707 f$

rsc.li/materials-advances

\title{
Advances in half-Heusler alloys for thermoelectric power generation
}

\begin{abstract}
Robert J. Quinn (D) and Jan-Willem G. Bos (D)*
Half-Heusler alloys are leading candidate materials for large scale thermoelectric power generation. In the past decade, substantial improvements have been made to the established $n$-types based on $\mathrm{X}_{\mathrm{IV}} \mathrm{NiSn}$, and exciting new $\mathrm{p}$-types based on $\mathrm{X}_{\mathrm{V}} \mathrm{FeSb}$ and $\mathrm{ZrCoBi}$ have been discovered. This has been achieved through careful experimental work and by increased fundamental insight. In particular, advances in materials synthesis and compositional optimisation guided by empirical modelling have been key to extracting more performance from half-Heuslers alloys. This review summarises recent progress for the main classes of half-Heusler alloys, including their fundamental electronic and thermal properties, processing, and thermoelectric performance. It also incorporates some of the expanding body of work focused on translating materials performance ( $z T>1$ at $773 \mathrm{~K}$ is now routinely possible) into generator devices.
\end{abstract}

\section{Introduction}

The world is currently undergoing a transition from an energy economy based on non-renewable fossil fuels to a system making use of a range of renewable generators including solar panels, wind turbines and hydroelectric plants, supplemented by nuclear energy. ${ }^{1}$ While major changes are taking place in terms of primary energy generation, work on improving the overall efficiency of the world's energy infrastructure is important, which can be achieved by improving electricity transmission, improving device efficiency, and recovering waste energy lost

Institute of Chemical Sciences and Centre for Energy Storage and Recovery, School of Engineering and Physical Sciences, Heriot-Watt University, Edinburgh, EH14 4AS, UK.E-mail: j.w.g.bos@hw.ac.uk

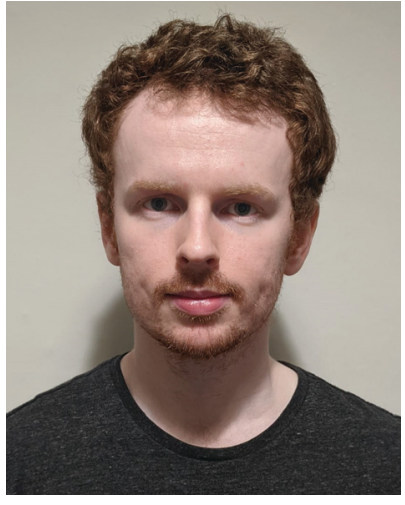

Robert J. Quinn
Dr Robert Quinn received his MChem degree in Chemistry from the University of Oxford (Exeter College) in 2017 and received his PhD from HeriotWatt University in 2021 following study on half-Heusler thermoelectric materials. He is currently a research associate on a Leverhulme Trust funded project, exploring metal phosphide phases as potential thermoelectric materials.

as heat. Thermoelectric generators (TEG's) turn a temperature gradient into an electrical current, allowing waste heat to converted back into electricity. ${ }^{2-7}$ The widespread application of TEG's would lead to a reduction in the energy production required by primary generators. TEG's can also be used as primary generators, in scenarios where maintenance is difficult, or a long lifetime is required. ${ }^{2-7}$

TEG's have temperature ranges in which they operate most effectively, due to the underlying material properties. ${ }^{8}$ The only commercial TEGs based on $\mathrm{Bi}_{2} \mathrm{Te}_{3}$ for example operate well from $300-500 \mathrm{~K}$, but their effectiveness begins to decrease at higher temperatures. For application involving higher temperatures a different material is required, such as PbTe and GeTe used in the Mars Perseverance rover. However, for large scale terrestrial applications, other requirements such as elemental abundance

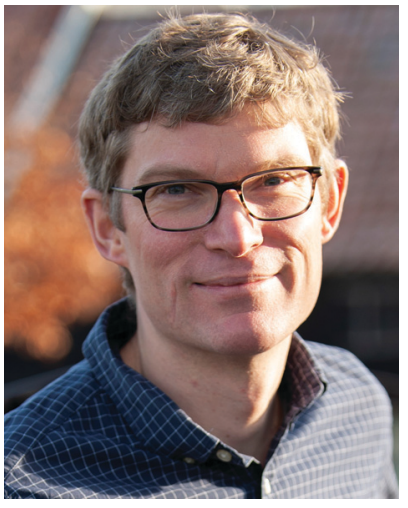

Jan-Willem G. Bos
Dr Jan-Willem Bos is an Associate Professor in Energy Materials at Heriot-Watt University. He is an experimental chemist with a broad interest in the synthesis, structure, and properties of inorganic solid-state materials. A large part of his current research is focused on the development of thermoelectric materials for waste heat recovery, including the half-Heuslers that are the topic of this review. 
and cost are important. ${ }^{9,10}$ Other factors are scalability of materials processing, mechanical properties, temperature stability, matching $\mathrm{n}$ - and p-type compositions and ease of electrical and thermal contacting within the TEG devices. ${ }^{4}$

Of all investigated bulk thermoelectric materials, the halfHeusler (HH) alloys hit most of these target criteria. ${ }^{11-16}$ In terms of outright performance, they are characterised by good electrical properties, making them suitable for power generation application, and are only held back by relatively high lattice thermal conductivities, which limit the overall heat to electricity conversion efficiency. Due to their good compromise between engineering properties and TE performance, $\mathrm{HH}$ alloys have received significant attention as potential thermoelectric materials. Initial investigations into these materials started in the late 1990s and identified n-type and p-type phases based on $\mathrm{X}_{\mathrm{IV}} \mathrm{NiSn}$ and $\mathrm{X}_{\mathrm{IV}} \operatorname{CoSb}\left(\mathrm{X}_{\mathrm{IV}}=\mathrm{Ti}, \mathrm{Zr}\right.$ and $\left.\mathrm{Hf}\right)$ as the most promising compositions. ${ }^{17-29}$ However, the difficulty in getting reproducible results and pushing $z T$ above one meant that other materials systems, in particular skutterudites and tellurides gained more prominence. ${ }^{6,7}$

For designing and quantifying the potential of a thermoelectric material, the figure of merit $(z T)$ is used: ${ }^{3}$

$$
z T=\frac{S^{2} \sigma}{\kappa} T
$$

where $S$ is the Seebeck coefficient, $\sigma$ is the electrical conductivity and $\kappa$ is the total thermal conductivity. $z T$ is maximised when electrical transport is high (large power factor $S^{2} \sigma$ ) and when thermal transport is low (small $\kappa$ ). $\kappa$ is made up of a lattice component $\left(\kappa_{\mathrm{l}}\right)$ due to vibrations, an electronic component $\left(\kappa_{\mathrm{el}}\right)$ due to heat carried by the charge carriers and in some cases a bipolar term $\left(\kappa_{\mathrm{bi}}\right)$ for semiconducting systems. Within a given material, optimisation of $z T$ involves adjusting the carrier concentration to find the optimal balance between a maximal $S^{2} \sigma$ and minimal $\kappa_{\mathrm{el}}$, whilst atomic substitutions (alloying) or nanostructuring can be used to reduce $\kappa_{\mathrm{l}}{ }^{8}$

The performance of a material is fundamentally determined by its electronic and phonon bandstructures. Another metric which describes this balance is the quality factor $(B)$, originally established in works by Goldsmid, Chasmar and Stratton: ${ }^{30-32}$

$$
B \propto \frac{\mu_{\mathrm{w}}}{\kappa_{\mathrm{l}}}
$$

where $\mu_{\mathrm{w}}$ is the weighted carrier mobility. In its simplest case, this is given by $\mu_{\mathrm{w}}=\mu_{0} m_{\mathrm{DoS}}^{* 3 / 2}$, where $\mu_{0}$ is the carrier mobility in the limit of zero carrier concentration and $m_{\text {DoS }}^{*}$ is the density of states effective mass. $B$ gives a measure of the quality of a thermoelectric material independent of the requirement to optimise the carrier concentration $n .^{30}$

Having a large $z T$ is not the only metric that needs to be considered when selecting a good thermoelectric material, and it has been noted that a reduction in $z T$ to improve the power output can be beneficial. ${ }^{33-35}$ A singular focus on $z T$ ignores the importance of $S^{2} \sigma$ for power generation, and on this metric the $\mathrm{HH}$ alloys are leading. As discussed below the $\mathrm{HH}$ alloys have intrinsic fairly large $\kappa_{1}$ values, and in terms of the quality factor,
$B$, their good performance derives from the large $\mu_{\mathrm{w}}$. This contrasts with many chalcogenides where high $B$ values are driven by glass-like $\kappa_{1}$ values. $^{6}$

Up to 2014, the main research focus was on developing n-type materials based on $\mathrm{X}_{\mathrm{IV}} \mathrm{NiSn}$ and $\mathrm{p}$-type materials based on $\mathrm{X}_{\mathrm{IV}} \mathrm{CoSb}$. This involved developing strategies for alloying and carrier doping and resulted in $z T \sim 1$ and $z T \sim 0.7$ at $773 \mathrm{~K}$ for the n-types and p-types respectively. ${ }^{14}$ Grain size reduction through high energy ball milling was also established as a route to lower $\kappa_{1}$ but was found to require small average grain sizes $0.2-0.3 \mu \mathrm{m}$ to be effective. ${ }^{14,36,37}$ The other route for optimisation that gained interest in the early 2010s was the use of phase segregation to embed favourable micro- and nanostructures for reduction of $\kappa_{\mathrm{l}}$. This focused in particular on segregation of X-site elements $(\mathrm{Ti}, \mathrm{Zr} \text { and } \mathrm{Hf})^{38-40}$ and excess metals, leading to incorporation of full-Heusler domains. ${ }^{41-45}$

Recent advances include the rise of p-type compositions $\mathrm{X}_{\mathrm{V}} \mathrm{FeSb}\left(\mathrm{X}_{\mathrm{V}}=\mathrm{V}, \mathrm{Nb}\right.$ and $\left.\mathrm{Ta}\right)$ and $\mathrm{ZrCoBi}$, each with $z T>1$ at $773 \mathrm{~K}^{46-48}$ It also includes the widespread use of single parabolic band (SPB) and Callaway modelling, ${ }^{15}$ coupled to first principles calculations, which have placed understanding of the $\mathrm{HH}$ alloys on a much firmer footing. This manuscript will review these main recent developments and will conclude with a brief overview of the integration of $\mathrm{HH}$ materials into working TEGs, which is attracting more and more interest.

This review is structured into 3 main sections. Section 2 will discuss general structural and processing aspects, and fundamental electronic and thermal properties of $\mathrm{HH}$ alloys. Section 3 gives an overview of key recent materials developments for the main classes of $\mathrm{HH}$ alloys. Section 4 gives a brief overview of incorporation into TEG devices.

\section{General trends in half-Heusler materials}

This section will describe some of the general trends in $\mathrm{HH}$ materials. This is focused on crystal structure and compositions, an overview of observed $z T$ and temperature-averaged $z T_{\mathrm{av}}$ values and general trends in electronic and thermal properties of these materials.

\subsection{Crystal structure}

$\mathrm{HH}$ alloys have a typical composition XYZ, where $\mathrm{X}$ is an early transition metal ( $\mathrm{Sc}, \mathrm{Ti}, \mathrm{V}$ groups), $\mathrm{Y}$ is a late transition metal (Fe, Co, Ni groups) and $\mathrm{Z}$ is a heavy main group metal (typically $\mathrm{Sn}$ or $\mathrm{Sb}$, occasionally $\mathrm{Ge}, \mathrm{Pb}$ or $\mathrm{Bi}) .{ }^{49}$ The structure can be described as a combination of zinc blende (YZ) and rock-salt (XZ) structures, with a $F \overline{4} 3 m$ (216) cubic space group, as shown in Fig. $1 .^{49,50} \mathrm{HH}$ materials with a valence electron count of 18 are semiconducting, as each element has either a filled or empty valence shell. For example in TiNiSn, the formal oxidation states are $\mathrm{Ti}^{4+}\left(3 \mathrm{~d}^{0}\right), \mathrm{Ni}^{0}\left(3 \mathrm{~d}^{10}\right)$ and $\mathrm{Sn}^{4-}\left(5 \mathrm{~s}^{2} 5 \mathrm{p}^{6}\right)$ and in $\mathrm{NbFeSb}$, they are $\mathrm{Nb}^{5+}\left(4 \mathrm{~d}^{0}\right), \mathrm{Fe}^{2-}\left(3 \mathrm{~d}^{10}\right)$ and $\mathrm{Sb}^{3-}\left(5 \mathrm{~s}^{2} 5 \mathrm{p}^{6}\right)$. Hence, each element has an empty/full shell and the oxidation states are balanced, signalling a stable composition. ${ }^{49-51}$ Similarly, one can 


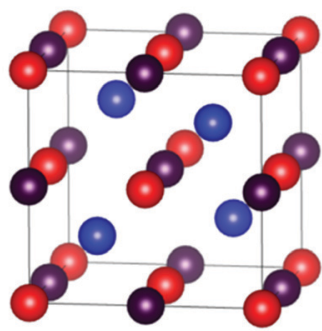

(a) Half-Heusler (XYZ)

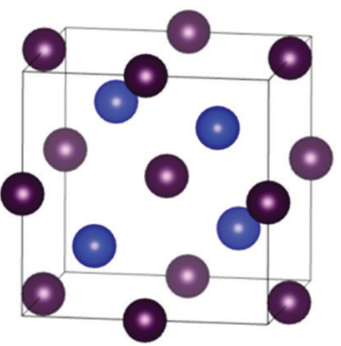

(c) Zinc Blende (YZ)

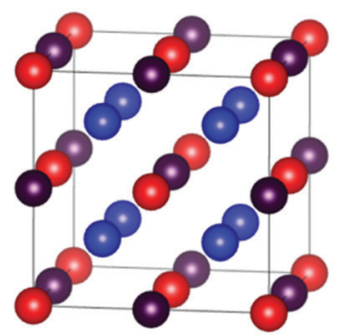

(b) Full-Heusler $\left(\mathrm{XY}_{2} \mathrm{Z}\right)$

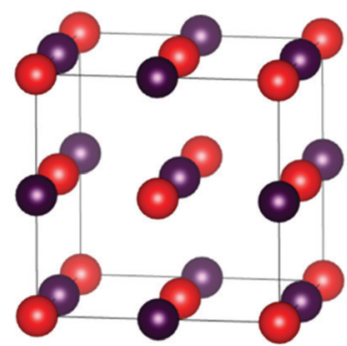

(d) Rock Salt (XZ)
Fig. 1 Unit cells of the (a) $X Y Z$ half-Heusler, (b) $X Y{ }_{2} Z$ full-Heusler, (c) $Y Z$ zinc blende and (d) $X Z$ rock salt structure types. These are all based on a face centred cubic lattice of $Z$ atoms (purple) but with different fillings of octahedral (red, $X$ atoms) and tetrahedral (blue, $Y$ atoms) sites. Alternatively, these structures can be described as containing multiple face centred cubic sublattices that are offset with respect to each other, e.g. in the half-Heusler structure, $X$ (red), $Y$ (blue), empty and Z (purple) sublattices are offset by $1 / 4$ along the body diagonal of the unit cell. This high symmetry arrangement, and possible partial occupancy of the second tetrahedral site, complicates reliable refinement of the atomic site occupancies in the half-Heusler structure.

consider the electronic structure to be related to III-V semiconductors, with an 18 electron [YZ] $]^{n-}$ zinc blende sublattice charge balanced by the electropositive metal $\mathrm{X}^{n+}{ }^{49}$ This electron counting does not fully guarantee a semiconducting state, with $\mathrm{HH}$ phases with higher average atomic number sometimes found to be semimetallic (e.g. HfCoSb), due to the closing of the band gap. ${ }^{19}$ It should also be noted that d-orbitals from the $\mathrm{X}$ and $\mathrm{Y}$ metals form the dominant contributions to the valence and conduction band, ${ }^{49}$ so the simple Zintl-model, with separate ionic $\mathrm{X}^{n+}$ and covalent $[\mathrm{YZ}]^{n-}$ substructures, does not fully capture the chemical bonding. ${ }^{52}$ First principles calculations confirm that the crystal structure is stabilised by strong covalent bonding in the $\mathrm{YZ}$ sublattice but also by stabilisation linked to the "ionic" XZ rocksalt sublattice, ${ }^{24,27}$ where (intuitively) site inversion would carry a large electrostatic penalty. Defect energy calculations confirm this picture with $\mathrm{X} / \mathrm{Z}$ and $\mathrm{Y} / \mathrm{Z}$ site inversion being costly, and the lowest energy defect generally being occupancy of the interstitial tetrahedral site. ${ }^{27,53-56}$ Full occupancy of the interstitial site leads to the $\mathrm{XY}_{2} \mathrm{Z}$ full-Heusler structure as shown in Fig. 1. As indicated by defect energy calculations, inversion of $\mathrm{X}$ and $\mathrm{Y}$ is uncommon (e.g. $<1 \%$ in $\left.\mathrm{X}_{\mathrm{IV}} \mathrm{NiSn}\right),{ }^{57}$ but there is evidence that this occurs for $\mathrm{V}_{0.8} \mathrm{CoSb}$ and $\mathrm{VFeSb},{ }^{58,59}$ where $\mathrm{V} / \mathrm{Fe}$ and $\mathrm{V} / \mathrm{Co}$ are (almost) adjacent in the periodic table and hence likely to have similar site preferences.

\subsection{Synthesis}

$\mathrm{HH}$ materials are intermetallic compounds and are usually prepared from elemental precursors, which span a range of melting points, e.g. $1855{ }^{\circ} \mathrm{C}$ for $\mathrm{Zr}$ and $232{ }^{\circ} \mathrm{C}$ for $\mathrm{Sn}$. Given the presence of refractory elements, melting has historically been the favoured route for initial reaction. Most frequently this is done by arc-melting of elemental pieces in an argon atmosphere, although levitation melting has become more common in recent years. ${ }^{60,61}$ The main advantage of levitation melting is that the sample does not touch the sample environment (usually a $\mathrm{Cu}$ plate in arc melting) and the presence of eddy currents that improve the homogeneity of the melt. ${ }^{48,60}$ Arc-melting has been noted to contain different microstructures in different sections of the final ingot. ${ }^{62}$ A linked practical advantage of melt-based routes is that larger elemental pieces can be used avoiding issues with surface oxidation that can be significant in powder metallurgy. Nevertheless, powder-based routes can give good performing samples, but care has to be taken with precursors, and the lower temperatures also place limitations on grain growth. ${ }^{59,63,64}$ Other means of achieving reaction include microwave synthesis and self-propagating combustion synthesis. ${ }^{65-69}$

After initial reaction it is common to anneal the sample, typically between $900-1000{ }^{\circ} \mathrm{C}$, to equilibrate the sample and increase homogeneity. In the past couple of years however, what may be called 'out-of-equilibrium' processing has gained much prominence. Here, melting is followed by ball milling and rapid consolidation at high temperature and under applied pressure, often using spark plasma sintering (SPS), but no long duration heating is used. ${ }^{47,48,70,71}$ This can be a favourable route that maintains embedded nanostructures that would be annealed out at high temperatures. ${ }^{72}$ In some instances, most notably for $\mathrm{ZrCoBi}$, the melting step is removed altogether, leading to an efficient synthetic protocol. ${ }^{48}$ Compared to the initial literature of the early 2000s, ball milling after $\mathrm{HH}$ phase formation has gained prominence and is now nearly always used. Reasons include promoting sample homogeneity and achieving a good particle size distribution that facilitates consolidation into dense ingots, whilst very small grain sizes are also beneficial for $\kappa_{1}$ reduction. ${ }^{36,37}$ Using direct mechanical alloying of elemental precursors has been found to narrow the grain size distribution in a range of $\mathrm{HH}$ materials, ${ }^{73}$ with $\mathrm{HH}$ and $\mathrm{FH}$ alloys forming during the milling stage. ${ }^{48,73,74}$ Ball milling needs to be carried out under an inert atmosphere, including the handling of the resulting fine powders, to protect the high surface area samples from oxidation.

Whether or not there is an annealing stage, all samples need to be in a highly dense form before property measurement. While samples can be cut from a melted piece with high density, ${ }^{75,76}$ it is more common for the powdered sample to be consolidated using either hot-pressing or SPS, with much of the improvement in thermoelectric performance in recent years arising due to more careful consolidation of samples. In particular, SPS has become more prominent and enables very rapid densification. ${ }^{77,78}$ In conventional hot pressing, uniaxial pressure is applied to the sample in a graphite die which is 
heated indirectly, for example using an induction coil. ${ }^{79}$ SPS applies a current directly through the graphite die, allowing for much more rapid heating of the sample. In some methods, such as flash-SPS, very short consolidation times on the order of minutes are possible. ${ }^{80,81}$ The choice of pressing method is expected to have an effect on the properties of the sample, with literature comparisons in other material systems showing significant differences in optical, thermal and mechanical properties. ${ }^{82-84}$

\subsection{Electronic transport properties}

HH thermoelectric materials are small band gap semiconductors, with calculated band gaps typically ranging between $0.5-1 \mathrm{eV}^{85}$ The conduction band minimum typically lies at the $X$-point, while the valence band will either exist at the $\Gamma$-point or the $L$-point, and in some cases, both can be effectively degenerate, as illustrated for the ZrCoBi system (Fig. 2). In addition, the $W$-point can sometimes be close to the other valence band maxima. From this perspective, $\mathrm{p}$-type materials have a larger potential for band-engineering to improve the thermoelectric properties, as degenerate band extrema allow for an increase in the density of states effective mass $\left(m_{\mathrm{DoS}}^{*}\right)$ :

$$
m_{\mathrm{DoS}}^{*}=\left(N_{\mathrm{V}}\right)^{\frac{2}{3}} m_{\mathrm{b}}^{*} \quad\left(N_{\mathrm{V}}=\sum_{i} N_{\mathrm{b}}^{i} N_{\mathrm{o}}^{i}\right)
$$

where $N_{\mathrm{V}}$ is the total carrier pocket degeneracy (where $N_{\mathrm{b}}$ is the number of bands contributing and $N_{\mathrm{o}}$ is the number of symmetry related pockets in the first Brillouin zone) in the electronic bandstructure and $m_{\mathrm{b}}^{*}$ is the band effective mass. Paradoxically, for good electronic performance a large $m_{\text {Dos }}^{*}$ is desirable for large $S$, but a low $m_{\mathrm{b}}^{*}$ is desirable for high $\sigma$. On balance a smaller $m_{\mathrm{b}}^{*}$ is better overall, yielding large $\mu_{\mathrm{w}}{ }^{86}$

As shown in Table $1, m_{\text {Dos }}^{*}$ for $\mathrm{HH}$ materials can be quite large, in some cases exceeding $10 m_{\mathrm{e}}$, with $m_{\mathrm{b}}^{*}$ typically between 1.5-3.0 $m_{\mathrm{e}}$, which requires large amounts of doping to reach optimal $n_{\mathrm{H}}$ up to orders of magnitude of $10^{20}-10^{21} \mathrm{~cm}^{-3}$. HH materials typically have $\mu_{\mathrm{H}}$ on the order of $10 \mathrm{~cm}^{2} \mathrm{~V}^{-1} \mathrm{~s}^{-1}$, with examples of single crystal ZrNiSn as large as $70 \mathrm{~cm}^{2} \mathrm{~V}^{-1} \mathrm{~s}^{-1}$ and $\mathrm{Ta}_{0.81}$ CoSb with $\mu_{\mathrm{H}}$ as low as $1.4 \mathrm{~cm}^{2} \mathrm{~V}^{-1} \mathrm{~s}^{-1}$. ${ }^{59,87}$ Here, $n_{\mathrm{H}}$ and $\mu_{\mathrm{H}}$ are the carrier concentration and mobility from Hall measurements.

As collection of Hall data has become more frequent, so have detailed investigations into the dominant carrier scattering mechanisms. For semiconductors at low doping concentrations $\left(n_{\mathrm{H}}<10^{17} \mathrm{~cm}^{-3}\right) \mu_{\mathrm{H}}$ is expected to be limited by ionised impurity (II) scattering, which has a characteristic $\mu_{\mathrm{H}} \sim T^{1.5}$ behaviour. ${ }^{88}$ At high doping concentration $\left(n_{\mathrm{H}}>10^{18} \mathrm{~cm}^{-3}\right)$, II scattering is minimal due to screening from the high number of charge carriers, and it is common to find scattering by phonons (acoustic phonon scattering; APS) to be dominant. This has a characteristic $\mu_{\mathrm{H}} \sim T^{-1.5}$ temperature dependence for semiconductors and $\mu_{\mathrm{H}} \sim T^{-1}$ in the metallic limit. ${ }^{88} \mathrm{~A}$ final intrinsic effect is alloy scattering (AS) due to size difference between alloying elements, with similar $n_{\mathrm{H}}$ dependence to APS but a different characteristic $\mu_{\mathrm{H}} \sim T^{-0.5}$ dependence. ${ }^{89,90}$ AS has been identified as the dominant carrier scattering mechanism a

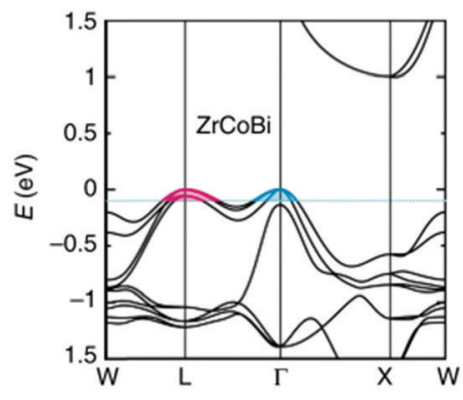

b

c

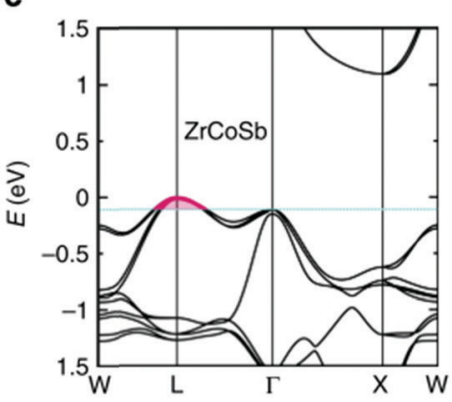

d

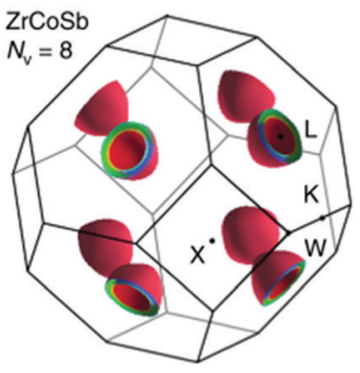

e
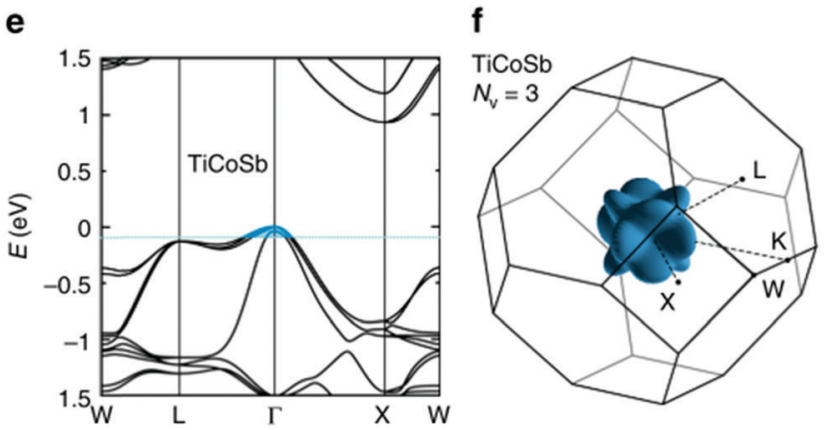

Fig. 2 First principles electronic bandstructures of XCoSb half-Heusler materials (including spin-orbit coupling contributions). As shown in (a) and (b), p-type doped $\mathrm{ZrCoBi}$ is expected to have carriers from the doubly degenerate $L$-point and $\Gamma$-point, leading to a substantial total degeneracy $N_{V}=10$. This is larger than many high-performance p-type half-Heusler phases, which have only $L$-point holes $\left(N_{V}=8\right)$, such as $\mathrm{ZrCoSb}$ as shown in (c) and (d). By contrast, TiCoSb only has carriers from the triply degenerate $\Gamma$-point $\left(N_{V}=3\right)$ as shown in (e) and (f) and is experimentally found to have the lowest power factor, $S^{2} \sigma$. Reproduced from Zhu et al. Nature Communications, $2018 .^{48}$

in a number of $\mathrm{HH}$ phases, ${ }^{91,92}$ with recent work indicating that this can be minimised by using alloying elements with similar sizes (minimising lattice strain). ${ }^{93}$ In other systems, the data suggests a dominant APS dependence, with the large $S^{2} \sigma$ in $\mathrm{HH}$ materials attributed to a fundamentally weak coupling of electrons with acoustic phonons, leading to high $\mu$ in spite of large $m_{\text {Dos }}^{*}{ }^{94}$

Electronic transport can also be affected by "extrinsic" scattering contributions arising from the materials microstructure. ${ }^{95}$ In particular, the impact of grain boundary (GB) resistances has attracted much recent interest. ${ }^{96-98}$ The most successful electronic transport models treat these materials as two-phase composites with bulk and GB phase contributions. The GB phase is usually modelled as a tunnel barrier (due to charge depletion in the GB region), accurately reproducing $\sigma(T)$ 
Table 1 Electronic bandstructure information of selected $\mathrm{HH}$ materials and experimental density of states effective mass ( $m_{\mathrm{Dos}}^{*}$, in electron mass units) obtained from Hall data as outlined in Appendix A. Here, $N_{b}$ is the number of bands at the valence or conduction band extrema, $N_{0}$ is the number of equivalent points in the Brillouin zone and $N_{v}$ is the total valley degeneracy

Type Point $N_{\mathrm{b}} N_{\mathrm{o}} N_{\mathrm{v}} m_{\text {Dos }}^{*} m_{\mathrm{b}} \quad$ Ref.

\begin{tabular}{|c|c|c|c|c|c|c|c|c|}
\hline $\mathrm{V}_{0.8+\delta} \mathrm{CoSb}$ & $\mathrm{n}$ & $X$ & & 3 & & 10.0 & & 59 \\
\hline $\mathrm{Nb}_{0.8+\delta} \mathrm{CoSb}$ & $\mathrm{n}$ & $X$ & $2^{a}$ & 3 & 6 & 7.7 & 2.33 & 183 and 188 \\
\hline $\mathrm{Ta}_{0.8+\delta} \mathrm{CoSb}$ & $\mathrm{n}$ & $X$ & & 3 & & 5.9 & & 59 \\
\hline $\mathrm{Zr}_{0.5} \mathrm{Hf}_{0.5} \mathrm{Co}_{1-x} \mathrm{Ni}_{x} \mathrm{Sb}$ & $\mathrm{n}$ & $X$ & 1 & 3 & 3 & 6.0 & 2.88 & 142 and 234 \\
\hline $\mathrm{Zr}_{1-x} \mathrm{Hf}_{x} \mathrm{CoSb}$ & $\mathrm{n}$ & $X$ & 1 & 3 & 3 & 6.5 & 3.13 & 93 \\
\hline $\mathrm{Ti}_{0.9-x} \mathrm{Hf}_{x} \mathrm{Ta}_{0.1} \mathrm{CoSb}$ & $\mathrm{n}$ & $X$ & 1 & 3 & 3 & 9.1 & 4.37 & 143 \\
\hline $\mathrm{ZrNi}_{1+x} \mathrm{Sn}$ & $\mathrm{n}$ & $X$ & 1 & 3 & 3 & 3.0 & 1.44 & 114 and 235 \\
\hline $\mathrm{TiNi}_{1+x} \mathrm{Sn}_{1-y} \mathrm{Sb}$ & $\mathrm{n}$ & $X$ & 1 & 3 & 3 & 2.8 & 1.35 & 175 and 235 \\
\hline $\mathrm{Ti}_{0.5} \mathrm{Zr}_{0.25} \mathrm{Hf}_{0.25} \mathrm{NiCu}_{x} \mathrm{Sn}$ & $\mathrm{n}$ & $X$ & $1^{b}$ & 3 & 3 & 4.1 & 1.97 & 64 and 235 \\
\hline $\mathrm{Zr}_{1-x} \mathrm{Hf}_{x} \mathrm{NiSn}_{0.985} \mathrm{Sb}_{0.015}$ & $\mathrm{n}$ & $X$ & 1 & 3 & 3 & 2.8 & 1.35 & 4 and 235 \\
\hline $\mathrm{Ti}_{1-x} \mathrm{Ta}_{x} \mathrm{Ni}_{0.92} \mathrm{Sn}$ & $\mathrm{n}$ & $X$ & 1 & 3 & $3^{c}$ & 4.5 & 2.16 & 71 and 235 \\
\hline $\mathrm{NbCoSn}_{1-x} \mathrm{Sb}$ & $\mathrm{n}$ & $X$ & 2 & 3 & 6 & 6.1 & 1.85 & 197 and 198 \\
\hline $\mathrm{ZrCo}_{1-x} \mathrm{Pd}_{x} \mathrm{Bi}$ & $\mathrm{n}$ & $X$ & 1 & 3 & 3 & 4.4 & 2.12 & 126 \\
\hline $\mathrm{ZrCo}_{1-x} \mathrm{Ni}_{x} \mathrm{Bi}$ & $\mathrm{n}$ & $X$ & 1 & 3 & 3 & 7.0 & 3.37 & 86 \\
\hline $\mathrm{Ta}_{1-x} \mathrm{Ti}_{x} \mathrm{FeSb}$ & $\mathrm{p}$ & $L$ & 2 & 4 & 8 & 9.0 & 2.25 & 47 \\
\hline $\mathrm{Nb}_{1-x} \mathrm{Hf}_{x} \mathrm{FeSb}$ & $\mathrm{p}$ & $L$ & 2 & 4 & 8 & 6.9 & 1.73 & 113 and 121 \\
\hline$\left(\mathrm{V}_{0.6} \mathrm{Nb}_{0.4}\right)_{1-x} \mathrm{Ti}_{x} \mathrm{FeSb}$ & $\mathrm{p}$ & $L$ & 2 & 4 & 8 & 10.0 & 2.50 & 119 \\
\hline $\mathrm{ZrCoBi}_{1-x} \mathrm{Sn}_{x}(x=0.2)$ & $\mathrm{p}$ & $L / \Gamma$ & $\begin{array}{l}2 / \\
2\end{array}$ & $\begin{array}{l}4 / \\
1\end{array}$ & 10 & $13^{d}$ & 2.80 & 48 and 86 \\
\hline $\mathrm{Ti}_{1-x} \mathrm{Hf}_{x} \mathrm{CoSb}_{0.85} \mathrm{Sn}_{0.15}$ & $\mathrm{p}$ & $L / \Gamma$ & $\begin{array}{l}2 / \\
3\end{array}$ & $\begin{array}{l}4 / \\
1\end{array}$ & 11 & 10.7 & 2.16 & 75 and 234 \\
\hline $\mathrm{Zr}_{1-x} \mathrm{Hf}_{x} \mathrm{CoSb}_{0.8} \mathrm{Sn}_{0.2}$ & $\mathrm{p}$ & $L$ & 2 & 4 & 8 & 12.5 & 3.13 & 92 \\
\hline
\end{tabular}

${ }^{a}$ Based on 19 electron NbCoSb with potentially larger $N_{\mathrm{b}}$ in the defective $\mathrm{Nb}_{0.8} \mathrm{CoSb}$ composition. ${ }^{b} \mathrm{Cu}$ interstitials may increase band degeneracy at the conduction band. ${ }^{c}$ Data suggests a higher $N_{\mathrm{v}}$ for this sample, see Section 3.5. ${ }^{d}$ Data suggests that $m_{\text {Dos }}^{*}$ increases with Sn substitution, as discussed in Section 3.2.

in a range of thermoelectrics, including $\mathrm{Mg}_{3} \mathrm{Sb}_{2}$ and $\mathrm{SrTiO}_{3} \cdot{ }^{96,97}$ GB scattering is particularly relevant for p-type $\mathrm{NbFeSb}$ with a very sensitive processing dependence of $S^{2} \sigma$, caused by changes in $\sigma(T)^{99}$ (also Section 3.1). It has also been observed in p-type
$\mathrm{ZrCoSb}$, where GB scattering is found to be substantial for low $n_{\mathrm{H}}$ and small grain sizes (Section 3.4). ${ }^{100}$

The recent availability of ZrNiSn single crystals has enabled in-depth investigation of the electronic properties. This includes collection of ARPES data on ZrNiSn that revealed a large intrinsic band gap $\sim 0.66 \mathrm{eV}$, comparable to DFT values $(\sim 0.5 \mathrm{eV})$ and unlike the $\sim 0.15 \mathrm{eV}$ values usually found from transport data due to in-gap states resulting from interstitial Ni. ${ }^{101}$ A comparison of single crystal and polycrystalline $\mathrm{ZrNiSn}_{1-y} \mathrm{Sb}_{y}$ samples reveals a complex carrier scattering phase diagram. With increasing $n_{\mathrm{H}}$ a crossover from II and GB scattering to APS and AS occurs near $300 \mathrm{~K}$, whilst at high temperature the transition is from polar optical (PO) phonon scattering to APS and AS. These transitions occur near $n_{\mathrm{H}}=$ $3-5 \times 10^{20} \mathrm{~cm}^{-3}$ and are a consequence of the effective screening of II, GB and PO scattering at higher carrier concentrations. ${ }^{87}$

\subsection{Thermal transport properties}

Compared to other state-of-the art thermoelectric materials, which benefit from ultralow $\left(<1 \mathrm{~W} \mathrm{~m}^{-1} \mathrm{~K}^{-1}\right) \kappa,{ }^{102,103}$ the $\mathrm{HH}$ family of materials typically have large $S^{2} \sigma$ and relatively high $\kappa$ values. This is partly due to large $\kappa_{1}$ as outlined above, but also due to large electronic $\left(\kappa_{\mathrm{el}}\right)$ values, consistent with the large reported $S^{2} \sigma$ values of these materials. Within the HH thermoelectric literature, experimental $\kappa_{\mathrm{l}}(T)$ data is typically treated using the Debye-Callaway model to describe the temperature dependence, with $\kappa_{1}(T)$ defined as: ${ }^{91,104,105}$

$$
\kappa_{\mathrm{l}}=\frac{k_{\mathrm{B}}}{2 \pi^{2} v_{\mathrm{s}}}\left(\frac{k_{\mathrm{B}} T}{\hbar}\right)^{3} \int_{0}^{\frac{\theta_{\mathrm{D}}}{T}} \frac{x^{4} \mathrm{e}^{x}}{\tau_{\mathrm{ph}^{-1}}\left(\mathrm{e}^{x}-1\right)^{2}} \mathrm{~d} x \quad\left(x=\frac{\hbar \omega}{k_{\mathrm{B}} T}\right)
$$

where $v_{\mathrm{s}}$ is the velocity of sound, $\theta_{\mathrm{D}}$ is the Debye temperature and $\tau_{\mathrm{ph}}{ }^{-1}$ is the total phonon scattering rate. Some publications also make use of the simplified Slack model. ${ }^{104,106}$ While work

Table 2 Overview of $300 \mathrm{~K}$ velocity of sound data for well-studied $\mathrm{HH}$ compositions. Here, $a_{\mathrm{HH}}$ is the lattice parameter. $v_{\mathrm{l}}, v_{\mathrm{t}}$ and $v_{\mathrm{avg}}$ are the longitudinal, transverse, and average velocities of sound. $\Theta_{\mathrm{D}}$ is the Debye temperature and $\gamma$ is the Grüneisen parameter. The latter two were obtained from $v_{l}$ and $v_{t}$ data as outlined in Appendix A. $\kappa_{l}^{U m k l a p p}$ is the $300 \mathrm{~K}$ lattice thermal conductivity for defect-free compositions, calculated using the DebyeCallaway model and assuming only Umklapp scattering. In many cases, experimental acoustic velocity of sound data is available (AC), other sources include calculations (DFT; materials project, MP) and for HfNiSn from mechanical measurements

\begin{tabular}{|c|c|c|c|c|c|c|c|c|c|}
\hline Composition & Source & $a_{\mathrm{HH}}(\AA)$ & $v_{1}\left(\mathrm{~m} \mathrm{~s}^{-1}\right)$ & $v_{\mathrm{t}}\left(\mathrm{m} \mathrm{s}^{-1}\right)$ & $v_{\mathrm{s}}\left(\mathrm{m} \mathrm{s}^{-1}\right)$ & $\Theta_{\mathrm{D}}(\mathrm{K})$ & $\gamma$ & $\kappa_{\mathrm{l}}^{\text {Umklapp }}\left(\mathrm{W} \mathrm{m}{ }^{-1} \mathrm{~K}^{-1}\right)$ & Ref. \\
\hline VFeSb & DFT & 5.769 & 5773 & 2974 & 3330 & 393 & 1.90 & 19.7 & 236 \\
\hline $\mathrm{NbFeSb}$ & $\mathrm{AC}$ & 5.950 & 5597 & 3099 & 3452 & 396 & 1.65 & 32.9 & 123 \\
\hline TaFeSb & $\mathrm{AC}$ & 5.938 & - & - & 2907 & 334 & - & - & 47 \\
\hline TaFeSb & DFT & 5.950 & 5115 & 2818 & 3140 & 360 & 1.64 & 33.4 & 113 \\
\hline TiCoBi & DFT & 6.033 & 4775 & 2736 & 3039 & 343 & 1.53 & 29.9 & 125 \\
\hline ZrCoBi & $\mathrm{AC}$ & 6.188 & 4613 & 2558 & 2849 & 314 & 1.64 & 23.2 & 48 \\
\hline HfCoBi & DFT & 6.194 & 4155 & 2353 & 2617 & 288 & 1.57 & 24.6 & 125 \\
\hline TiCoSb & $\mathrm{AC}$ & 5.882 & 5691 & 3230 & 3591 & 416 & 1.56 & 35.6 & 141 \\
\hline $\mathrm{ZrCoSb}$ & $\mathrm{AC}$ & 6.070 & 5488 & 3144 & 3493 & 392 & 1.53 & 37.9 & 141 \\
\hline HfCoSb & $\mathrm{AC}$ & 6.039 & 4703 & 2709 & 3008 & 340 & 1.51 & 34.1 & 141 \\
\hline TiNiSn & $\mathrm{AC}$ & 5.930 & 5426 & 3062 & 3406 & 392 & 1.58 & 29.0 & 237 \\
\hline ZrNiSn & $\mathrm{AC}$ & 6.110 & 5498 & 3149 & 3498 & 390 & 1.53 & 37.4 & 237 \\
\hline HfNiSn & Mech. & 6.080 & 4191 & 2503 & 2770 & 311 & 1.38 & 31.4 & 238 \\
\hline $\mathrm{V}_{0.8+\delta} \mathrm{CoSb}$ & $\mathrm{AC}$ & 5.795 & 5437 & 2902 & 3242 & 381 & 1.78 & 21.0 & 191 \\
\hline $\mathrm{Nb}_{0.8+\delta} \mathrm{CoSb}$ & $\mathrm{AC}$ & 5.902 & 5581 & 2987 & 3336 & 385 & 1.77 & 26.2 & 183 \\
\hline $\mathrm{Ta}_{0.8+\delta} \mathrm{CoSb}$ & MP-31459 & 5.969 & 4650 & 2323 & 2607 & 297 & 2.00 & 12.8 & 239 and 240 \\
\hline NbCoSn & DFT & 5.946 & 5625 & 3016 & 3368 & 386.09 & 1.762 & 26.7 & 196 \\
\hline TaCoSn & DFT & 5.948 & 4955 & 2761 & 3077 & 352.30 & 1.6268 & 31.6 & 196 \\
\hline
\end{tabular}


on calculating $\kappa_{1}$ from the phonon bandstructure exists, ${ }^{107-113}$ it is more typical to use approximations based on calculated elastic properties or experimental acoustic properties to estimate $v_{\mathrm{s}}, \theta_{\mathrm{D}}$ and $\tau_{\mathrm{ph}}$. The most fundamental description of $\tau_{\mathrm{ph}}$ considers Umklapp scattering, which can be written as: ${ }^{105}$

$$
\frac{1}{\tau_{\mathrm{U}}}=2 \gamma^{2} \frac{k_{\mathrm{B}} T}{G V_{0}} \frac{\omega^{2}}{\omega_{\mathrm{D}}}
$$

where $\gamma$ is the Grüneisen anharmonicity parameter, $G$ is the Shear modulus and $V_{0}$ is the volume per atom. Assuming only Umklapp scattering and grain boundary scattering equivalent to grain size of $100 \mu \mathrm{m}, \kappa_{1}(300 \mathrm{~K})$ for $\mathrm{HH}$ materials can be calculated to be around $20-40 \mathrm{~W} \mathrm{~m}^{-1} \mathrm{~K}^{-1}$ as shown in Table 2 and Fig. 3. Experimental velocity of sound values obtained directly from acoustic measurements have been used where possible and used
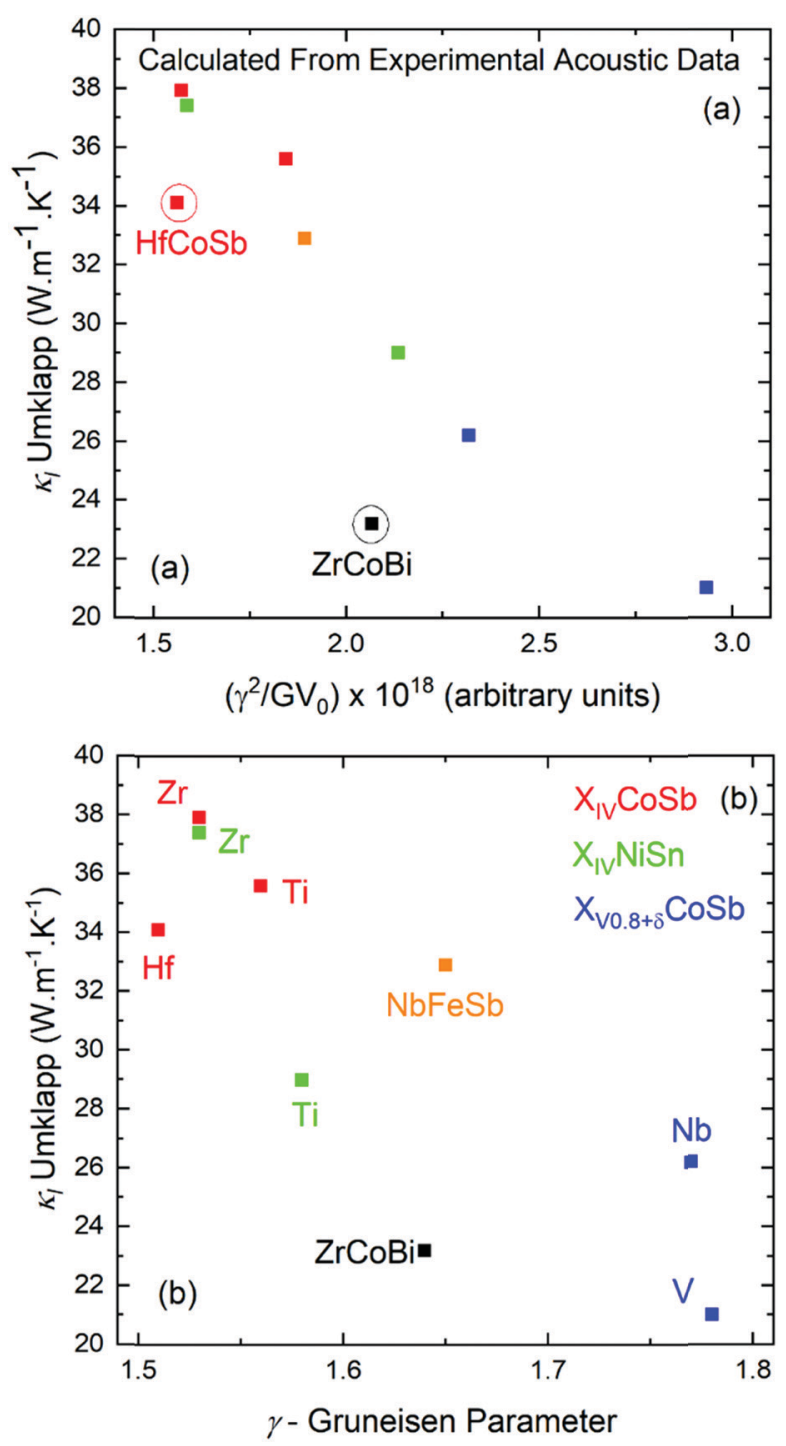

Fig. 3 Plots of calculated lattice thermal conductivity $\left(\kappa_{l}\right)$ at $300 \mathrm{~K}$ (see Section 2.4), assuming the presence of only Umklapp scattering (i.e. for the defect free parent materials), versus (a) the variables determining the magnitude of Umklapp scattering and (b) the acoustic Grüneisen parameter. $\mathrm{HfCoSb}$ and $\mathrm{ZrCoBi}$ have lower $\kappa_{l}$ due to low $v_{\mathrm{s}}$ (see Table 2). to calculate $\gamma$ and $G$ (see Appendix). The volume per atom has been calculated using the reported lattice parameter $\left(a_{\mathrm{HH}}\right)$.

As the scattering rate, $\tau_{\mathrm{U}}{ }^{-1}$ increases, $\kappa_{\mathrm{l}}$ is expected to decrease, which is illustrated well in Fig. 3a, with the outliers being ZrCoBi and HfCoSb due to their low $\theta_{\mathrm{D}}$. TaFeSb also has low $\theta_{\mathrm{D}}$ and is another outlier, but is not included in Fig. 3, since only the average velocity of sound was reported..$^{47}$ In the plot of $\kappa_{1}$ vs. $\gamma$ in Fig. $3 \mathrm{~b}$, there is a larger spread due to lower $v_{\mathrm{t}}$ for TiNiSn and $\mathrm{V}_{0.8+\delta} \mathrm{CoSb}$ (yielding a larger $\gamma$ ) versus their second row analogues. This is ultimately corrected for by a larger $G$, giving a relatively smooth dependence in Fig. 3a. Naturally these values only represent an upper limit for $\kappa_{\mathrm{l}}$, and the measured experimental values don't get close to $40 \mathrm{~W} \mathrm{~m}^{-1} \mathrm{~K}^{-1}$. Within the Debye-Callaway model, phonon scattering can be expected to arise due to grain boundaries, the existence of point defects and electron-phonon interactions. Even small effects can have a large effect on $\kappa_{1}$. In ZrNiSn for example, introducing a point defect scattering term $\Gamma=0.02$ is enough to reduce $\kappa_{1}$ from $37 \mathrm{~W} \mathrm{~m}{ }^{-1} \mathrm{~K}^{-1}$ to $17 \mathrm{~W} \mathrm{~m}^{-1} \mathrm{~K}^{-1}$, which is the value expected from a $2 \%$ Hf impurity (which is typical in commercial elemental $\mathrm{Zr}$ ). Small amounts of interstitials are also sufficient to embed this amount point defect disorder and have been linked to strongly suppressed $\kappa_{1}$ values in $\mathrm{X}_{\mathrm{IV}} \mathrm{NiSn}$ and $\mathrm{X}_{\mathrm{IV}} \mathrm{CoSb}$ systems. ${ }^{63,114}$

In addition to $\kappa_{\mathrm{l}}, \mathrm{HH}$ thermoelectrics usually have significant $\kappa_{\mathrm{el}}$, due to the large carrier concentrations and bipolar transport at high temperatures. The total $\kappa_{\mathrm{el}}$ is given by: ${ }^{115}$

$$
k_{\mathrm{el}}=\left(L_{\mathrm{n}} \sigma_{\mathrm{n}}+L_{\mathrm{p}} \sigma_{\mathrm{p}}\right) T+\frac{\sigma_{\mathrm{n}} \sigma_{\mathrm{p}}}{\sigma_{\mathrm{n}}+\sigma_{\mathrm{p}}}\left(S_{\mathrm{p}}-S_{\mathrm{n}}\right)^{2} T
$$

Here, the first term is the Wiedemann-Franz $\left(\kappa_{\mathrm{WF}}\right)$ electronic thermal conduction due to the flow of electron $\left(\sigma_{\mathrm{n}}\right)$ and hole $\left(\sigma_{\mathrm{p}}\right)$ currents, which simplifies to $\kappa_{\mathrm{WF}}=L \sigma T$ if the Lorenz numbers $\left(L_{\mathrm{n} / \mathrm{p}}\right)$ for electrons and holes are identical. ${ }^{115}$ The second term is the bipolar thermal conductivity $\left(\kappa_{\mathrm{bi}}\right)$, which is linked to carrier recombination due to the presence of opposing electron and hole currents. ${ }^{115}$ Here $S_{\mathrm{n} / \mathrm{p}}$ are the partial Seebeck coefficients of the n- and p-type carriers. The measured $S$ is given by: ${ }^{115}$

$$
S=\frac{S_{\mathrm{n}} \sigma_{\mathrm{n}}+S_{\mathrm{p}} \sigma_{\mathrm{p}}}{\sigma_{\mathrm{n}}+\sigma_{\mathrm{p}}}
$$

$\kappa_{\text {bi }}$ can be significant at high temperatures for materials with small band gaps, where a large number of minority carriers can be easily excited. From eqn (7), this also leads to a simultaneous degradation of $S$, leading to a rapid drop in the thermoelectric figure of merit, $z T$. In the context of the $\mathrm{HH}$ thermoelectrics, this situation applies to the n-type $\mathrm{X}_{\mathrm{IV}} \mathrm{NiSn}$ materials, which have small band gaps, $E_{\mathrm{g}} \sim 0.5 \mathrm{eV}$ from DFT calculations and $\sim 0.15 \mathrm{eV}$ from transport and optical measurements. ${ }^{116}$ Most p-types have much larger band gaps and are not strongly affected.

\subsection{Overview of materials efficiency: $z T$ and $z T_{\text {avg }}$}

The most commonly used metric to quantify the thermoelectric performance of a single material is the materials figure of merit $(z T)$. A larger $z T$ is expected to translate into higher efficiency in 
a thermoelectric device. However, a more appropriate metric of performance is the temperature average of $z T$ over the gradient the TEG operates under. For this review we have used the following equation: ${ }^{117,118}$

$$
z T_{\mathrm{avg}}=\frac{\int_{T_{\mathrm{C}}}^{T_{\mathrm{H}}} z T \mathrm{~d} T}{T_{\mathrm{H}}-T_{\mathrm{C}}}
$$

Fig. 4 shows $z T$ and $z T_{\text {avg }}$ for some of the most promising $\mathrm{HH}$ materials found in the literature. The best n-type materials based on $\mathrm{X}_{\mathrm{IV}} \mathrm{NiSn}$ achieve large $z T$ at 600-900 K (Fig. 4a), reaching a peak due to a gradual decline in $S(T)$ and increase in $\kappa_{\mathrm{bi}}(T)$ at high temperatures. The n-type $\mathrm{X}_{\mathrm{IV}} \mathrm{CoSb}$ and $\mathrm{X}_{\mathrm{V} 0.8} \mathrm{CoSb}$ examples shown have a lower $z T$, but they maintain a growth in $z T$ up to $1100 \mathrm{~K}$, potentially making them more suitable at higher temperatures than the $\mathrm{X}_{\mathrm{IV}} \mathrm{NiSn}$ systems.

The best p-type samples all show a gradual increase in $z T$ at least up to $1200 \mathrm{~K}$, at their best achieving $z T \sim 1.5$. The overall lower $z T$ for the p-types means that where $z T_{\text {avg }}$ would approach 1 at $800 \mathrm{~K}$ for the best n-type materials, it takes until $1200 \mathrm{~K}$ to reach similar $z T_{\text {avg }}$ for p-type $\mathrm{HH}$ phases. From Fig. $4 \mathrm{c}$ and $\mathrm{d}$, it is clear that the $\mathrm{p}$-type $\mathrm{X}_{\mathrm{IV}} \mathrm{CoSb}$ materials have been overtaken rapidly by the new wave of $\mathrm{ZrCoBi}$ and $\mathrm{X}_{\mathrm{V}} \mathrm{FeSb}$ systems.

\section{Recent developments in half-Heusler materials}

In the following an overview of the main recent materials development will be given, starting with the new p-type materials, followed by good n-types and then other compositions of interest.

\section{1. $X_{V} F e S b\left(X_{V}=V, N b\right.$ and Ta) (p-type)}

In 2014, promising p-type thermoelectric properties were reported for $\left(\mathrm{V}_{0.6} \mathrm{Nb}_{0.4}\right)_{1-x} \mathrm{Ti}_{x} \mathrm{FeSb}$, with moderately large $S^{2} \sigma$ around $3 \mathrm{~mW} \mathrm{~m}{ }^{-1} \mathrm{~K}^{-2}$ and quite small $\kappa_{\mathrm{l}}$ below $3 \mathrm{~W} \mathrm{~m}^{-1} \mathrm{~K}^{-1}$, yielding peak $z T_{900 \mathrm{~K}}=0.8$ for $x=0.2 .{ }^{119}$ The good performance in this series was attributed to large $m_{\mathrm{DoS}}^{*}=10 m_{\mathrm{e}}$ and consequently large $S(T)$, combined with significant X-site alloy point defect scattering suppressing $\kappa_{\mathrm{l}}$. This 'heavy hole' behaviour is the main characteristic of the $\mathrm{X}_{\mathrm{V}} \mathrm{FeSb}$ family (and for the other p-type $\mathrm{HH}$ materials) and arises due to a doubly degenerate $L$-point valence band maxima with $N_{\mathrm{v}}=8$ (Table 1). ${ }^{119,120}$ Consequently, high doping levels between $10^{21}-10^{22} \mathrm{~cm}^{-3}$ are required to optimise the thermoelectric performance at high temperatures, which was not achieved in this initial report. It only took one year for the same group to report $z T_{1200 \mathrm{~K}}=1.5$ for the composition
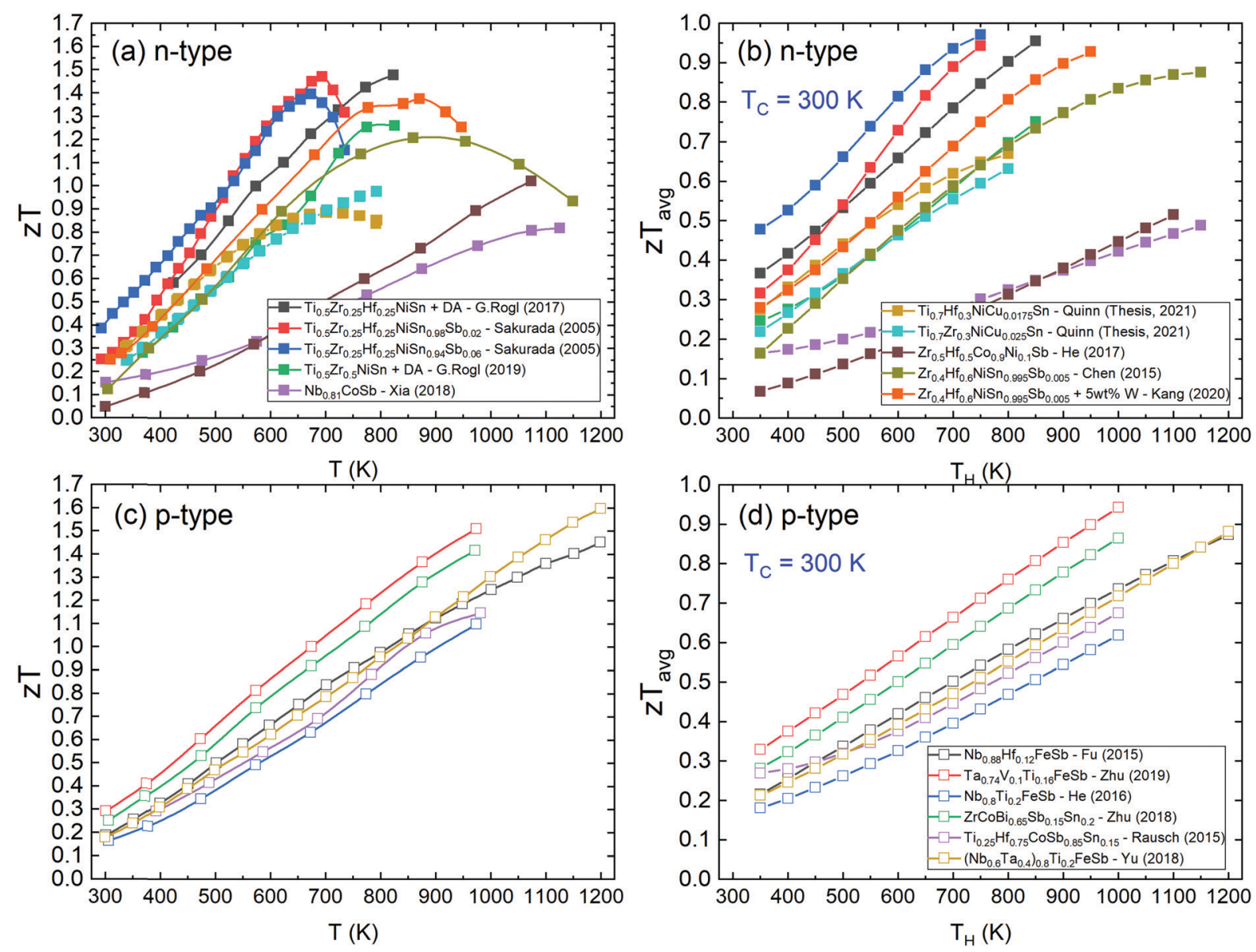

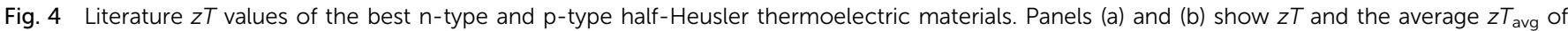

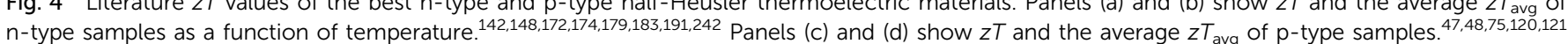

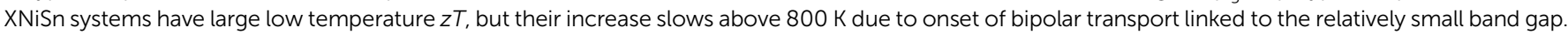


$\mathrm{Nb}_{0.88} \mathrm{Hf}_{0.12} \mathrm{FeSb}^{121}$ This material removes all $\mathrm{V}$ from the system, resulting in a decrease in $m_{\mathrm{DoS}}^{*}$ to $6.9 m_{\mathrm{e}}$ reducing the doping required to reach the optimal $S^{2} \sigma$, with the increased $\mu_{\mathrm{H}}$ resulting in a near doubling of $S^{2} \sigma$ to between 5-6 $\mathrm{mW} \mathrm{m}^{-1} \mathrm{~K}^{-2}$. In addition to p-type doping the material, Hf substitution introduces X-site alloy point defect scattering, maintaining low $\kappa_{1}$. Further success was found in TaFeSb, for which the composition $\mathrm{Ta}_{0.74} \mathrm{~V}_{0.1} \mathrm{Ti}_{0.16} \mathrm{FeSb}$ uses the same approach of combined carrier doping and phonon scattering using $\mathrm{Ti}$, with a small fraction of $\mathrm{V}$ used to further suppress $\kappa_{1}$ and push $z T_{973 \mathrm{~K}}$ from 1.39 to $1.52 .{ }^{47}$ The largest peak $z T$ reported for $\mathrm{X}_{\mathrm{V}} \mathrm{FeSb}$ materials comes from the $\left(\mathrm{Nb}_{1-x} \mathrm{Ta}_{x}\right)_{0.8} \mathrm{Ti}_{0.2} \mathrm{FeSb}$ series, with both $x=0.36$ and 0.4 reaching $z T_{1200 \mathrm{~K}}=1.6,{ }^{48}$ As can be seen in Fig. $4 \mathrm{c}$ however, the magnitude of $z T$ is lower for the $\left(\mathrm{Nb}_{1-x} \mathrm{Ta}_{x}\right)_{0.8} \mathrm{Ti}_{0.2} \mathrm{FeSb}$ series closer to room temperature (leading to a lower $z T_{\text {avg }}$ in Fig. $4 d$ ), perhaps due to the weaker mass disorder provided by $\mathrm{Nb}$.

Perhaps the most impressive feature of this family is the ability to achieve extremely large $S^{2} \sigma$ between $5-6 \mathrm{~mW} \mathrm{~m}^{-1} \mathrm{~K}^{-1}$ over a wide temperature range. ${ }^{4-48,121-123}$ As first reported in 2016, careful processing allows for $S^{2} \sigma_{300 \mathrm{~K}}>10 \mathrm{~mW} \mathrm{~m}^{-1} \mathrm{~K}^{-2}$ to be achieved in $\mathrm{Nb}_{0.95} \mathrm{Ti}_{0.05} \mathrm{FeSb}$, using a hot pressing temperature of $1100{ }^{\circ} \mathrm{C}$ to eliminate the parasitic electrical resistance from grain boundary scattering observed with lower pressing temperatures, as illustrated in Fig. 5. ${ }^{99}$ This was later also demonstrated for the analogous systems with $\mathrm{Zr}$ and Hf dopants. ${ }^{123}$ In addition to the very large $S^{2} \sigma$, the $\kappa_{1}(T)$ achieved in $\mathrm{Ta}_{0.74} \mathrm{~V}_{0.1} \mathrm{Ti}_{0.16} \mathrm{FeSb}$ is extremely low for a $\mathrm{HH}$ material, starting at $\kappa_{\mathrm{l}, 300 \mathrm{~K}}=2.3 \mathrm{~W} \mathrm{~m} \mathrm{~W}^{-1} \mathrm{~K}^{-1}$ decreasing to $\kappa_{1,300 \mathrm{~K}}=1.6 \mathrm{~W} \mathrm{~m}^{-1} \mathrm{~K}^{-1}$, with mass disorder from $\mathrm{Ti} / \mathrm{V}$ substitution proving to be effective at suppressing $\kappa_{\mathrm{l}}{ }^{47}$

A range of synthetic routes have been used to prepare $\mathrm{X}_{\mathrm{V}} \mathrm{FeSb}$ $\mathrm{HH}$ materials. The initial reports on $\left(\mathrm{V}_{0.6} \mathrm{Nb}_{0.4}\right)_{1-x} \mathrm{Ti}_{x} \mathrm{FeSb}$ and $\mathrm{Nb}_{1-x} \mathrm{Hf}_{x} \mathrm{FeSb}$ used levitation melting, mechanical milling, SPS and a short annealing step at a low temperature of $750{ }^{\circ} \mathrm{C} .{ }^{119,121}$ The TaFeSb based samples were prepared directly from the elements using ball milling (in a shaker mill), followed by direct current hot-pressing (similar to SPS) for only two minutes at $850{ }^{\circ} \mathrm{C}$, with no subsequent annealing step. ${ }^{47}$ This report does not establish whether the $\mathrm{HH}$ phase forms during the milling step, or whether reaction takes place during hot pressing with the assistance of finely dispersed powder precursors. In spite of the well documented benefit on $\sigma_{\mathrm{RT}}$ of a $1100{ }^{\circ} \mathrm{C}$ densification temperature for $\mathrm{Nb}_{1-x} \mathrm{Ti}_{x} \mathrm{FeSb}$ (Fig. 5), highly doped $\mathrm{Ta}_{1-x} \mathrm{Ti}_{x} \mathrm{FeSb}$ samples seem to suffer no detriment from the relatively low $850{ }^{\circ} \mathrm{C}$ pressing temperature (although $x<0.06$ samples seem to suffer from grain boundary effects). ${ }^{47}$ This suggests that these systems have a different grain boundary chemistry. Note that due to the higher melting point of Ta compared to $\mathrm{Nb}$, a priori smaller grain sizes and a more pronounced impact on $\sigma_{\mathrm{RT}}$ might have been expected. However, this does not appear to be the case. To conclude, the $\mathrm{X}_{\mathrm{V}} \mathrm{FeSb}$ materials are blessed with naturally excellent electronic properties and thermal transport, which can be easily suppressed using well established mass disorder techniques.

\section{2. $\quad$ ZrCoBi (p-type)}

In $2018, \mathrm{ZrCoBi}_{0.65} \mathrm{Sb}_{0.15} \mathrm{Sn}_{0.2}$ was reported to have the then largest $z T_{973 \mathrm{~K}}=1.42$ for any $\mathrm{p}$-type $\mathrm{HH}$ phase. ${ }^{48}$ This composition
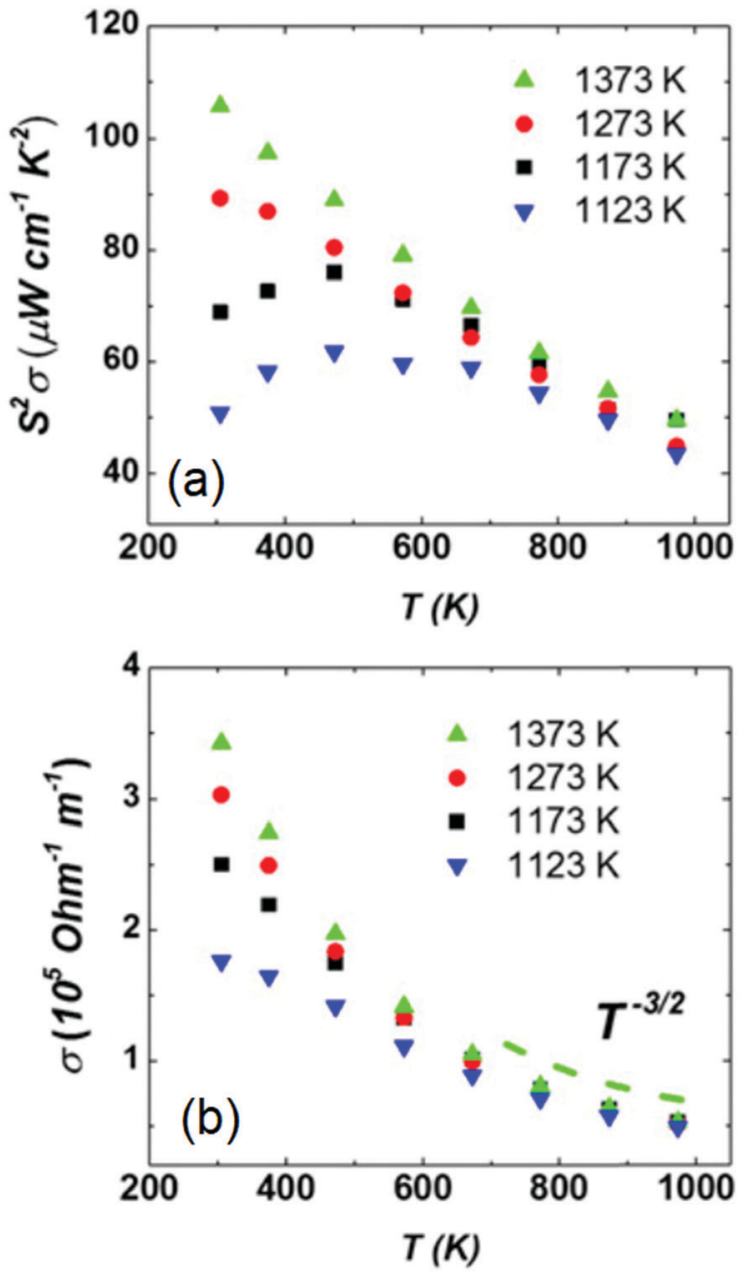

Fig. 5 The effect of hot-pressing temperature on the electronic properties of $\mathrm{Nb}_{0.95} \mathrm{Ti}_{0.05} \mathrm{FeSb}$. As seen in (a) hot-pressing at $1100{ }^{\circ} \mathrm{C}$ leads to over double the power factor, $S^{2} \sigma$ at $300 \mathrm{~K}$, relative to pressing at $950{ }^{\circ} \mathrm{C}$. As illustrated in (b) this enhancement arises due to an increase in $\sigma_{300 k}$, attributed to the elimination of grain boundary scattering of charge carriers. Reproduced from He et al. PNAS, 2016 . $^{99}$

benefits from a large $N_{\mathrm{v}}=10$, which arises due to degenerate $\Gamma$ and $L$ (Table 1) valence band maxima, which is an inherent property of the stoichiometric $\mathrm{ZrCoBi}$ phase (Fig. 2). This convergence translates to large $m_{\mathrm{DoS}}^{*}$, with the reported Hall data suggesting that $m_{\text {DoS }}^{*}$ increases from around $9 m_{\mathrm{e}}$ to $13 m_{\mathrm{e}}$ with $\mathrm{Sn}$ substitution up to $x=0.2$ in the $\mathrm{ZrCoBi}_{1-x} \mathrm{Sn}_{x}$ solid solution (Table 1). ${ }^{48,86} \mathrm{~A}$ combination of $\mathrm{Sn}$ and $\mathrm{Sb}$ alloying is successful in suppressing $\kappa_{1}$ and optimising the carrier concentration, with the parent composition already having a markedly lower $\kappa_{1}$ than many $\mathrm{HH}$ phases due to the high mass of $\mathrm{Bi}$ and a low velocity of sound, $v_{\mathrm{s}}$ (Table 2). As was the case for $\mathrm{TaFeSb},{ }^{47}$ the $\mathrm{ZrCoBi}$ samples were prepared via ball milling the constituent elements and then direct current hot pressing for 5 minutes at $900{ }^{\circ} \mathrm{C}^{48} \mathrm{In}$ this report the $\mathrm{HH}$ phase was found to form directly after the milling step. No further experimental work has emerged on p-type $\mathrm{X}_{\mathrm{IV}} \mathrm{CoBi}$ materials since, although two separate computational investigations of $\mathrm{X}_{\mathrm{IV}} \mathrm{CoBi}$ materials also find near degenerate $\Gamma$ and $L$ point valence band maxima in TiCoBi 
and HfCoBi. ${ }^{124,125}$ It was discovered, however, that n-type ZrCoBi is also a promising thermoelectric material, reaching $z T_{973 \mathrm{~K}}=1$ for $\mathrm{ZrCo}_{0.9} \mathrm{Ni}_{0.1} \mathrm{Bi}_{0.85} \mathrm{Sb}_{0.15}$, again utilising a ball-milling to pressing synthetic protocol. ${ }^{86}$ As before $\mathrm{Bi} / \mathrm{Sb}$ alloying is used to suppress $\kappa_{\mathrm{l}}$, but interestingly $\mathrm{Co} / \mathrm{Ni}$ alloying also reduces $\kappa_{\mathrm{l}}$ significantly, despite minimal expected mass and strain differences. The reported $m_{\mathrm{DoS}}^{*}=7 m_{\mathrm{e}}$ is quite large considering the low band degeneracy of the $X$-point, suggesting a large $m_{\mathrm{b}}$, consistent with the reported low mobility. In the previous year n-type $\mathrm{ZrCo}_{1-x} \mathrm{Pd}_{x} \mathrm{Bi}$ was reported with substantially lower $z T$, due to a combination of significantly larger $\kappa_{1}$ and a much lower $m_{\text {Dos }}^{*}=4.4 m_{\mathrm{e}}{ }^{126}$ The samples in this report were prepared using arc-melting, ball-milling and rapid uniaxial hot-pressing.

\section{3. $\quad \mathrm{X}_{\mathrm{IV}} \mathrm{CoSb}\left(\mathrm{X}_{\mathrm{IV}}=\mathrm{Ti}, \mathrm{Zr}\right.$ and Hf) (p-type)}

Before the rapid emergence of the high $z T$ p-type $\mathrm{X}_{\mathrm{V}} \mathrm{FeSb}$ and ZrCoBi materials, $\mathrm{X}_{\mathrm{IV}} \mathrm{CoSb}$ materials were by far the most promising candidate p-type $\mathrm{HH}$ phases. $z T_{1073 \mathrm{~K}}=1.0$ had been achieved for $\mathrm{Ti}_{0.2} \mathrm{Hf}_{0.8} \mathrm{CoSb}_{0.8} \mathrm{Sn}_{0.2}$ in 2012, with the same achieved in a 2013 follow up report on $\mathrm{Ti}_{0.12} \mathrm{Zr}_{0.44} \mathrm{Hf}_{0.44} \mathrm{CoSb}_{0.8} \mathrm{Sn}_{0.2}$, with both utilising X-site alloying and milling to suppress $\kappa_{\mathrm{l}} \cdot{ }^{127,128}$ Once again, these p-type compositions benefit from high $m_{\mathrm{Dos}}^{*}$ due to the doubly degenerate $L$-point valence band maximum (Table 1 ),

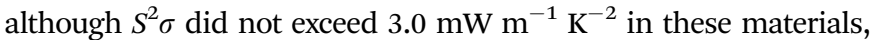
with a fundamentally low $\mu_{\mathrm{H}}$ in this system. The modest $S^{2} \sigma$ is a serious drawback for these compositions, as there are few clear-cut ways to improve the electronic properties and $z T$, whereas a range of strategies are available to suppress $\kappa_{\mathrm{l}}$. In $2015 z T$ was pushed up to 1.15 at $973 \mathrm{~K}$ for the composition $\mathrm{Ti}_{0.25} \mathrm{Hf}_{0.75} \mathrm{CoSb}_{0.85} \mathrm{Sn}_{0.15}$, by optimising $n_{\mathrm{H}}$ and X-site alloying, with phase segregation into Ti-rich and Hf-rich regions credited with further suppression of $\kappa_{\mathrm{l}}{ }^{75}$ Another important detail in this paper is while $m_{\text {DoS }}^{*} \sim$ $10.7 m_{\mathrm{e}}$ remains largely constant in the $\mathrm{Ti}_{1-x} \mathrm{Hf}_{x} \mathrm{CoSb}$ solid solution, $\mu_{\mathrm{H}}$ is around 3 times lower in TiCoSb than HfCoSb, which makes the expensive element $\mathrm{Hf}$ key to high performance. ${ }^{75}$ Studies into the stability of the phase segregation revealed both $z T$ and microstructure to remain unchanged upon repeated temperature cycling. ${ }^{129,130}$ Another drawback of TiCoSb is that it appears to be more susceptible to oxidation than other HHs. ${ }^{131-137}$

Since 2015, there hasn't been any increase in $z T$ in the p-type $\mathrm{X}_{\mathrm{V}} \mathrm{CoSb}$ materials, although work on these materials continues. ${ }^{138,139}$ An extensive investigation into the $\mathrm{Zr}_{1-x} \mathrm{Hf}_{x} \mathrm{CoSb}_{1-y} \mathrm{Sn}_{y}$ system determined that the temperature dependence of hole mobility is consistent with alloy scattering $\left(\mu_{\mathrm{H}} \sim T^{-0.5}\right)$, in stark contrast to the $\mathrm{X}_{\mathrm{V}} \mathrm{FeSb}$ materials, which have temperature dependences consistent with acoustic phonon scattering. ${ }^{92}$

The above reports generally make use of arc-melting to react elemental pieces, although a 2021 report eliminated the melting step, simply ball-milling elemental precursors and hot-pressing at $1000{ }^{\circ} \mathrm{C} .{ }^{140}$ This study equalled the record with $z T_{975 \mathrm{~K}}=1.1$ for this family with the composition $\mathrm{Ti}_{0.4} \mathrm{Hf}_{0.6}$ $\mathrm{CoSb}_{0.83} \mathrm{Sn}_{0.17}$, with suppressed $\kappa_{\mathrm{l}}$ and $S^{2} \sigma \cdot{ }^{140}$ While this is a positive result, it also illustrates that $\kappa_{1}$ can't be suppressed further using $\mathrm{Ti}$ without also suppressing the electronic performance.

\section{4. $\mathrm{X}_{\mathrm{IV}} \operatorname{CoSb}\left(\mathrm{X}_{\mathrm{IV}}=\mathrm{Ti}, \mathrm{Zr}\right.$ and $\left.\mathrm{Hf}\right)$ (n-type)}

The $\mathrm{X}_{\mathrm{IV}} \mathrm{CoSb}$ materials are unusual in that good $z T$ values are possible in both $\mathrm{n}$ - and p-type doped compositions. The n-type materials have the $X$-point conduction band minimum shared amongst all 18 electron $\mathrm{HH}$ phases (Fig. 2). Despite the fact that $\mathrm{X}_{\mathrm{IV}} \mathrm{CoSb}$ materials have long been known to be intrinsically $\mathrm{n}$ type ${ }^{141}$ reports on competitive $z T$ have only emerged in the last 4-5 years. $^{93,142}$ Initially, Ni substitution was used to dope $\mathrm{Zr}_{0.5} \mathrm{Hf}_{0.5} \mathrm{CoSb}$, with $z T_{1073 \mathrm{~K}}=1$ achieved in $\mathrm{Zr}_{0.5} \mathrm{Hf}_{0.5} \mathrm{Co}_{0.9} \mathrm{Ni}_{0.1} \mathrm{Sb}$, with moderate $S^{2} \sigma$ vales exceeding $3.25 \mathrm{~mW} \mathrm{~m}^{-1} \mathrm{~K}^{-2}$ and once again suppressed $\kappa_{\mathrm{l}}$ due to X-site alloying. ${ }^{142} \mathrm{~A} m_{\mathrm{DoS}}^{*} \sim 6 m_{\mathrm{e}}$ was confirmed in subsequent reports on other n-type compositions, with $\left(\mathrm{Zr}_{1-x} \mathrm{Hf}_{x}\right)_{1-y} \mathrm{Nb}_{y} \mathrm{CoSb}$ having $m_{\text {DoS }}^{*} \sim 6.5 m_{\mathrm{e}} \cdot{ }^{93,100}$ Although the $\mathrm{Nb}$ doped materials don't exceed $z T=1$, the initial report used Callaway analysis to show that the X-site alloying in these materials suppresses $\kappa_{\mathrm{l}}$ without causing any reduction in $\mu_{\mathrm{H}}$. This is consistent with the earlier observation that minimising the size mismatch between dopant/alloying elements helps maintain good $\mu_{\mathrm{H}}$ values, ${ }^{93}$ whilst mass disorder effectively reduces $\kappa_{\mathrm{l}}$. These studies have also shown that n-type TiCoSb is substantially more promising than its p-type counterpart, ${ }^{139}$ with the composition $\mathrm{Ti}_{0.6} \mathrm{Hf}_{0.3} \mathrm{Ta}_{0.1} \mathrm{CoSb}$ reaching $z T_{973 \mathrm{~K}}=0.9 .^{143}$

A subsequent study on $\left(\mathrm{Hf}_{0.3} \mathrm{Zr}_{0.7}\right)_{0.94} \mathrm{Nb}_{0.06} \mathrm{CoSb}$ established that $\sigma_{300 \mathrm{~K}}$ can be heavily suppressed by grain boundary scattering, introduced by intense ball-milling used to reduce grain size. ${ }^{100}$ This leads to semiconducting behaviour near $300 \mathrm{~K}$, while at high temperatures degenerate semiconducting behaviour is observed. Hence, as was seen for $\mathrm{NbFeSb}$, care must be taken when processing $\mathrm{HH}$ phases to prevent grain boundary scattering of charge carriers. At present all n-type $\mathrm{X}_{\mathrm{IV}} \mathrm{CoSb}$ materials reported use a melting, milling and pressing procedure, but this may simply reflect the novel nature of these compositions and a lack of detailed processing studies.

\section{5. $\mathrm{X}_{\mathrm{IV}} \mathrm{NiSn}\left(\mathrm{X}_{\mathrm{IV}}=\mathrm{Ti}, \mathrm{Zr}\right.$ and $\left.\mathrm{Hf}\right)$ (n-type)}

The $\mathrm{X}_{\mathrm{IV}} \mathrm{NiSn}$ compositions are very much the original $\mathrm{HH}$ thermoelectric, ${ }^{17,18,20,21,24-27,144-147}$ with the 2005 report of $z T_{700 \mathrm{~K}}=1.5$ driving a significant amount of interest in $\mathrm{HH}$ thermoelectrics. ${ }^{148}$ As shown in Fig. 4, $z T$ values from this report have never been fully matched, contrary to the expected evolution of material optimisation, which sees a gradual increase in $z T$ over the years.

The $\mathrm{X}_{\mathrm{IV}} \mathrm{NiSn}$ phases have some unique properties relative to the other $\mathrm{HH}$ alloys. The $\mathrm{X}_{\mathrm{IV}} \mathrm{NiSn}$ materials have the lowest reported $m_{\mathrm{DoS}}^{*} \sim 3 m_{\mathrm{e}}$ amongst the high $z T$ materials, which arises due to a combination of low $N_{\mathrm{v}}=3$ and low $m_{\mathrm{b}}^{*} \sim 1.7 m_{\mathrm{e}}$ (Table 1). This means that lower doping levels are required to optimise $S^{2} \sigma$, and in several instances the best performance comes for $\sim 1-2 \%$ atomic substitution, ${ }^{148-150}$ contrasting with $15-20 \%$ required for the p-types.

An additional factor to consider is the interstitial site and the full-Heusler $\mathrm{XNi}_{2} \mathrm{Sn}$ phase. ${ }^{41-44,54,57,71,72,151-166}$ The interstitial site is the vacant 8-coordinate (tetrahedral coordination to $\mathrm{X}$ and $\mathrm{Z}$ ) site in the material (sometimes referred to as the Wyckoff $4 \mathrm{~d}$ or tetrahedral site), which is fully occupied in the 
FH structure (Fig. 1). ${ }^{49}$ Even stoichiometric $\mathrm{X}_{\mathrm{IV}} \mathrm{NiSn}$ materials commonly form with a few percent occupation of the interstitial site, with an $\mathrm{X}_{\mathrm{IV}} / \mathrm{Sn}$ binary phase formed to compensate. ${ }^{41,43,45,57,72,160}$ Preparing compositions with intentional metal excess, $\mathrm{X}_{\mathrm{IV}} \mathrm{Ni}_{1+x} \mathrm{Sn}$ is possible, although there is a limit to $x$, past which a FH phase begins to form. ${ }^{151,154,155}$ Both interstitial Ni acting as point defects or $\mathrm{FH}$ nanoinclusions have been claimed to be useful for scattering phonons. ${ }^{63,72}$ The pursuit of $\mathrm{FH}$ nanoinclusions was a major focus for $\mathrm{X}_{\mathrm{IV}} \mathrm{NiSn}$ investigations in the early 2010s. ${ }^{14}$ The presence of interstitial $\mathrm{Ni}$ is also cited as reducing the observed electronic band gap. ${ }^{71,116}$

$\mathrm{X}$-Site phase segregation. Initial success in reproducing the large reported $z T$ values came from work focusing on X-site phase segregation. This is based on the limited mutual solidity of $\mathrm{Ti}$ and $\mathrm{Zr} / \mathrm{Hf}$, whereas $\mathrm{Zr}$ and $\mathrm{Hf}$ with a more similar size are fully miscible. ${ }^{167}$ Reports by Schwall and Balke, and Populoh et al. yielded $z T_{830 \mathrm{~K}}=1.2$ with the low $\kappa_{1}$ underpinning the good performance linked to phase segregation. ${ }^{38,40}$ Phase segregation due to limited solubility between $\mathrm{Ti}, \mathrm{Zr}$ and $\mathrm{Hf}$ is expected from firstprinciples, with only the solid solution between ZrNiSn and HfNiSn expected to be stable at $300 \mathrm{~K}$, although full $\mathrm{Ti} / \mathrm{Zr}(\mathrm{Hf})$ solubility is predicted to be possible above $600 \mathrm{~K} .{ }^{168}$ This phase segregation behaviour has been observed routinely in these materials through powder diffraction and SEM analysis..$^{38-40,57,64,169-171}$ Phase segregation is not simply a case of the formation of two distinct phases, with Ti alloyed compositions containing several $\mathrm{HH}$ phases discernible by diffraction. This can be ascribed in large part to low expected diffusion rates of the $\mathrm{X}_{\mathrm{IV}}$ site atoms, leading to regions with kinetically trapped compositions resulting from the melting stage. ${ }^{39,168}$ Interestingly, SEM and SXRD data for $\mathrm{Ti}_{0.5} \mathrm{Zr}_{0.25} \mathrm{Hf}_{0.25}$ $\mathrm{NiCu}_{y} \mathrm{Sn}$ prepared by a powder route (never exceeding $850{ }^{\circ} \mathrm{C}$ ) shows an increasing homogenisation on the $\mathrm{X}_{\mathrm{IV}}$ site with increasing $\mathrm{Cu}$ content, ${ }^{64}$ which was attributed to the presence of a molten $\mathrm{Cu}-\mathrm{Sn}$ phase that improves the reaction kinetics during synthesis.

The approach which was able to reduce $\kappa_{1}$ the most used a convoluted synthetic protocol consisting of arc-melting, induction-melting, annealing, an undisclosed "densification aid", ball-milling and finally hot-pressing. ${ }^{172}$ This work also aimed to exploit X-site phase segregation by initial heating above the spinodal line and subsequent heat treatment just below to force nanoscale segregation. However, the paper itself does not provide direct microscopy confirmation. Nevertheless, the composition $\mathrm{Ti}_{0.5} \mathrm{Zr}_{0.25} \mathrm{Hf}_{0.25} \mathrm{NiSn}(+\mathrm{DA})$ was reported to have a very low $\kappa_{1} \sim 1.8 \mathrm{~W} \mathrm{~m}^{-1} \mathrm{~K}^{-1}$ at $300 \mathrm{~K}$, while maintaining a large $S^{2} \sigma$, enabling $z T_{823 \mathrm{~K}}=1.5 .^{172}$ Outside of this report, the group is able to consistently achieve $z T_{800 \mathrm{~K}}>1$ with the assistance of a "densification aid" that is considered to improve electrical contacting of the grains. ${ }^{173,174}$ In the composition $\mathrm{Ti}_{0.5} \mathrm{Zr}_{0.5} \mathrm{NiSn}$ for example, the addition of the "densification aid" increases $S^{2} \sigma$ at $700 \mathrm{~K}$ from $\sim 2.5 \mathrm{~W} \mathrm{~m}{ }^{-1} \mathrm{~K}^{-2}$ to $\sim 4 \mathrm{~W} \mathrm{~m}^{-1} \mathrm{~K}^{-2}$, and coupled to a low $\kappa_{\mathrm{l}}$ this enables $z T>1 .^{174}$

Interstitial metals and FH inclusions. Investigations into the nature of excess $\mathrm{Ni}$ in these materials has progressed since our 2014 review. ${ }^{14}$ Calculations investigating the $\mathrm{X}_{\mathrm{IV}} \mathrm{NiSn} / \mathrm{X}_{\mathrm{IV}} \mathrm{Ni}_{2} \mathrm{Sn}$ solid solution have explored the stability of interstitial $\mathrm{Ni}$ and experimental work has been performed to find the limits of interstitial occupancy. ${ }^{53,72,114,151,160,175-177}$ In well-annealed samples $\left(T>800{ }^{\circ} \mathrm{C}\right)$, the solubility of interstitials is highest in TiNiSn $\left(x_{\max }=0.06-0.08\right.$ at $\left.900{ }^{\circ} \mathrm{C}\right),{ }^{160}$ whilst $x_{\max } \leq 0.03$ for ZrNiSn and HfNiSn. ${ }^{178}$ The solubility of Ni interstitials increases with temperature, consistent with the entropy stabilised nature of this defect. ${ }^{53}$ Full-Heusler (nano)inclusions can be stabilised by (rapid) cooling from the melt, but exposure to $T>800{ }^{\circ} \mathrm{C}$ leads to the gradual dissolution of $\mathrm{FH}$ inclusion, ${ }^{72}$ and conversion to interstitials and distinct (macroscopically segregated) $\mathrm{FH}$ phases that are discernible in diffraction. Due to the link to processing (i.e. cooling from the melt), the experimental $4 \mathrm{~d}$ site occupancies can far exceed equilibrium values, with electronic properties recorded for $\mathrm{ZrNi}_{1+x} \mathrm{Sn}$ with $x>0.1 .^{114,161}$ Unpublished neutron powder diffraction data from our group confirms $x \leq 0.18$ in arc-melted $\mathrm{ZrNi}_{1+x} \mathrm{Sn}$ ingots, although this decreases to $x=0.03$ when annealed at $900{ }^{\circ} \mathrm{C}$ (in agreement with the phase diagram), with the excess $\mathrm{Ni}$ forming $\mathrm{FH}$ regions visible by diffraction. The trapping of large amounts of excess $\mathrm{Ni}$ (in out of equilibrium samples) likely explains most of the variations in reported $\mathrm{TE}$ properties for nominally similar samples, but with different processing (thermal) histories. The impact of $\mathrm{Ni}$ interstitials and inclusions is profound with strong reductions of $\kappa_{1}$ and electron mobility evident. $^{72,160}$

Property measurements have confirmed the significance of interstitials on the thermoelectric properties, with excess $\mathrm{Ni}$ suppressing $\kappa_{1}$ by up to $70 \%$ in the $\mathrm{TiNi}_{1+x} \mathrm{Sn}$ and $\mathrm{ZrNi}_{1+x} \mathrm{Sn}$ system. ${ }^{72,160,161,175}$ Callaway analysis demonstrates that $\mathrm{Ni} / \mathrm{Cu}$ interstitials have a similar impact to vacancies with additional disorder contribution due to bond formation. ${ }^{63,160}$ For the $\mathrm{Ti}_{1-x} \mathrm{Ta}_{x} \mathrm{Ni}_{0.92} \mathrm{Sn}$ system, the intentional $\mathrm{Ni}$ deficiency (with the aim of obtaining stoichiometric TiNiSn) leads to an increase in both $\kappa_{\mathrm{l}}$ and $\mu_{\mathrm{H}}$, with the improved electronic properties leading to a net increase in $z T$ (Fig. 6). ${ }^{71}$ At low temperatures, the Ni deficiency leads to a substantial increase in $\sigma$, while at higher temperatures $S$ is enhanced, leading to a minimum of $35 \%$ increase in $S^{2} \sigma(T)$ across the entire temperature range.

Using appropriate processing, excess $\mathrm{Ni}$ can also be stabilised as $\mathrm{FH}$ (nano)inclusions in the $\mathrm{HH}$ matrix, acting an extrinsic source of phonon and electron scattering. Chai et al. reported success in preparing composite $\mathrm{ZrNi}_{1.1} \mathrm{Sn}$ with significantly improved thermoelectric properties relative to the stoichiometric composition, attributed largely to a dispersion of nanoscale $\mathrm{FH}$ inclusions. $^{44,72,153,167}$ DTA analysis suggested the $\mathrm{FH}$ phases 'dissolve' into the $\mathrm{HH}$ matrix above $800{ }^{\circ} \mathrm{C}$, and reform with a smaller domain size when cooled. ${ }^{72}$ These nanoscale $\mathrm{FH}$ inclusions suppress $\kappa_{1}$ by up to $40 \%$, leading to a $\sim 40 \%$ increase in $z T_{\max }$ from 0.54 to 0.75 , compared to the first heating cycle. In addition to these melt-based routes, the Poudeu group has reported extensively on nanocomposite $\mathrm{HH}$ samples prepared using a high-temperature solid-state route. ${ }^{42,156,157}$ Carrier filtering was reported to improve $S^{2} \sigma$ and reductions in $\kappa_{\mathrm{l}}$ were observed, with a highest $z T=0.8$ at $800 \mathrm{~K}$.

Recently it was found that $\mathrm{W}$ nanoinclusions are highly effective in reducing $\kappa_{1}$ by $20 \%$ while simultaneously enhancing $S^{2} \sigma$ by up to $33 \%$. $\mathrm{Hf}_{0.6} \mathrm{Zr}_{0.4} \mathrm{NiSn}_{0.99} \mathrm{Sb}_{0.01}+5 \mathrm{wt} \% \mathrm{~W}$ has peak $z T_{773 \mathrm{~K}}=1.4 .^{179}$ This would seem to be a successful 

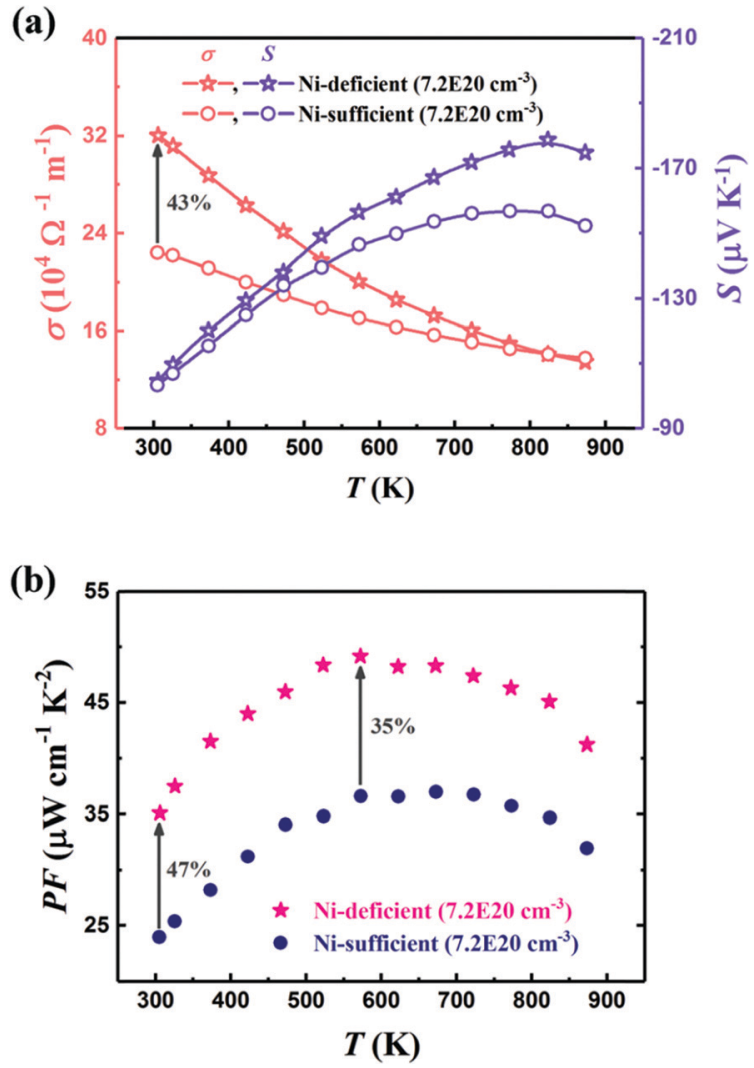

Fig. 6 The effect of nominal Ni deficiency in the $\mathrm{Ti}_{1-x} \mathrm{Ta}_{x} \mathrm{Ni}_{1-\delta} \mathrm{Sn}$ system, in samples with identical carrier concentration, $n_{\mathrm{H}}$. As seen in (a), nominal $\mathrm{Ni}$ deficiency causes a substantial increase in $\mu_{\mathrm{H}}$ at $300 \mathrm{~K}$ and enhances $S(T)$ at high temperatures. This leads to a significant increase in power factor, $S^{2} \sigma$ as seen in (b). Reproduced from Ren et al. 2019, Advanced Electronic Materials. ${ }^{71}$

implementation of the nanoinclusion effect (i.e. carrier filtering and reductions in $\kappa_{1}$ ) that had been previously considered to be possible with nanoscale $\mathrm{FH}$ inclusions. The introduction of $\mathrm{W}$ in these samples was achieved by ball milling $\mathrm{W}$ nanoparticles into premade HH samples, followed by SPS for densification. The cycling stability was confirmed for 10 cycles up to $1073 \mathrm{~K}$, suggesting the composition is sufficiently stable for application.

While $m_{\text {Dos }}^{*}$ in ZrNiSn and HfNiSn have been well established as being close to $3.0 \mathrm{~m}_{\mathrm{e}}$, the value for TiNiSn based materials is less clear. ${ }^{114}$ Data on Sb-doped $\mathrm{TiNi}_{1+x} \mathrm{Sn}$ samples from 2018 show a similar $m_{\text {Dos }}^{*} \sim 2.8 m_{\mathrm{e}}$, which seems to be robust up to $700 \mathrm{~K} .{ }^{175}$ Data from high performance $\mathrm{Ti}_{1-x} \mathrm{Ta}_{x} \mathrm{Ni}_{0.92} \mathrm{Sn}$ samples however are more consistent with $m_{\text {Dos }}^{*} \sim 4.5 m_{\mathrm{e}}{ }^{71}$ Given that both reports place $\mu_{\mathrm{H}}$ between $20-30 \mathrm{~cm}^{2} \mathrm{~V}^{-1} \mathrm{~s}^{-1}$ at room temperature, there does not appear to be a significant increase in $m_{\mathrm{b}}^{*}$ (which would lead to a significant decrease in $\mu_{\mathrm{H}}$ ). Considering eqn (3), the increase in $m_{\text {Dos }}^{*}$ should be attributed to an increase in $N_{\mathrm{v}}$. Our reported data on $\mathrm{TiNiCu}_{0.075} \mathrm{Sn}$, which uses interstitial $\mathrm{Cu}$ to n-type dope the material, gives a relatively large values of $\sim 5.5 \mathrm{me}_{\mathrm{e}}{ }^{63}$ Similarly Hall data for the $\mathrm{Ti}_{0.5} \mathrm{Zr}_{0.25} \mathrm{Hf}_{0.25} \mathrm{NiCu}_{y} \mathrm{Sn}$ series conform to $m_{\text {Dos }}^{*}=4.1 m_{\mathrm{e}}$, including the undoped sample. ${ }^{64}$ Some data in the $\mathrm{Ti}_{1-x} \mathrm{Hf}_{x} \mathrm{NiSn}_{1-y} \mathrm{Sb}_{y}$ series also suggests $m_{\text {DoS }}^{*}=3.9 m_{\mathrm{e}} \cdot{ }^{180}$ While the large $m_{\text {DoS }}^{*}$ in the $\mathrm{Ti}_{1-x} \mathrm{Ta}_{x} \mathrm{Ni}_{0.92} \mathrm{Sn}$ system was not addressed, first principles calculations on the interstitial $\mathrm{Cu}$-doped materials suggest the appearance of a second conduction band minimum in the electronic bandstructure, supporting the idea that the increase in $m_{\text {DoS }}^{*}$ is caused by to an increase in $N_{\mathrm{v}}{ }^{64}$

Given the high volume of publications on the $\mathrm{X}_{\mathrm{IV}} \mathrm{NiSn}$ system, a number of protocols outside of melting, ball-milling and hot-pressing/SPS exist, with TiNiSn being the target of most experimentation. Microwave synthesis has reported for TiNiSn, achieving a peak $z T_{740 \mathrm{~K}}=0.45 .{ }^{65}$ In 2019 Zilber et al. successfully grew TiNiSn single crystals from a Sn flux, with lower $n_{\mathrm{H}}$ and larger $S$ than typically reported in polycrystalline samples. ${ }^{181}$ Similarly $\mathrm{ZrNiSn}_{1-y} \mathrm{Sb}_{y}$ crystals can be grown and extracted by centrifuging, with improved $\mu_{\mathrm{H}}$ compared to high quality polycrystalline samples. ${ }^{87}$

Self-propagating synthesis for exothermic processes allows for the heat produced from initial reaction to drive the reaction to completion, as has been demonstrated for $\mathrm{ZrNiSn}^{66,69} \mathrm{In}$ a custom pressing setup, the heat released from the reaction (initiated by Tungsten electrode) was enough to densify the pellet, with a $T_{\max }=1668 \mathrm{~K}$ achieved by the self-propagating reaction. ${ }^{66}$

The large literature pool also allows for comparisons to be made in how the $\mathrm{HH}$ phases form, which is important when planning microstructure and defects. ZrNiSn and HfNiSn are known form congruently from the molten state, while TiNiSn prefers to form the $\mathrm{TiNi}_{2} \mathrm{Sn} \mathrm{FH}$ phase. ${ }^{155,176,177}$ Similarly TiNiSn decomposes when heated above $1450 \mathrm{~K}$. The rapid solidification achieved by melt-spinning is claimed to be able to suppress formation of $\mathrm{TiNi}_{2} \mathrm{Sn}$ from the molten state. ${ }^{182}$ It remains the case that melting, milling and hot-pressing/SPS give the best thermoelectric performance.

Overall, for the $\mathrm{X}_{\mathrm{IV}} \mathrm{NiSn}$ compositions, it remains challenging to optimise the thermoelectric properties. This is related to the tendency for significant deviations from nominal stoichiometry, phase segregation and the small electronic bandgap, which leads to significant bipolar transport at high temperatures. Elimination of interstitial $\mathrm{Ni}$ is desirable as this would increase the electronic bandgap, hence reducing the minority carrier conduction and improving the high temperature $z T$.

\section{6. $\quad \mathrm{X}_{\mathrm{Vo} .8} \operatorname{CoSb}\left(\mathrm{X}_{\mathrm{V}}=\mathrm{V}, \mathrm{Nb}\right.$ and Ta) (n-type)}

Perhaps the most significant recent discovery for the n-type $\mathrm{HH}$ materials is promising thermoelectric performance in the nominally 19 electron $\mathrm{X}_{\mathrm{V}} \mathrm{CoSb}$ compositions..$^{59,183-188}$ As a stoichiometric phase, these materials are expected to be metallic with the possibility of ferromagnetism. ${ }^{189}$ In 2016, the material VCoSb was synthesised with $S(T)$ significantly larger than what is typical of a fully metallic sample, although $n_{\mathrm{H}}$ was quite large at $\sim 1.6 \times 10^{22} \mathrm{~cm}^{-3} \cdot{ }^{185}$ The properties of this phase and the subsequently investigated $\mathrm{NbCoSb}$ and $\mathrm{TaCoSb}$ phases were discovered to be due to X-site vacancies, ${ }^{187,188}$ which reduce the overall electron count without depleting electronic states in the valence band, which is easily understood through the valence electron counting $\mathrm{X}^{n+}[\mathrm{YZ}]^{n-}$ description introduced earlier. 
To reach a theoretically semiconducting state one would need to reach the composition $\mathrm{X}_{\mathrm{V} 0.8} \mathrm{CoSb}$ (Fig. 7). Each of the $\mathrm{X}_{\mathrm{V}} \mathrm{CoSb}$ phases forms with a different vacancy fraction, with the $\mathrm{V}$ phase forming preferentially as $\mathrm{V}_{0.87} \mathrm{CoSb}$, the $\mathrm{Nb}$ phase as $\mathrm{Nb}_{0.85} \mathrm{CoSb}$, while the Ta phase forms close to being 'fully' vacant at $\mathrm{Ta}_{0.81} \operatorname{CoSb}^{59} n_{\mathrm{H}}$ is dependent on the vacancy fraction as has been demonstrated for the $\mathrm{Nb}_{0.8+\delta} \mathrm{CoSb}$ system, ${ }^{183} \mathrm{So} \mathrm{V}_{0.87} \mathrm{CoSb}$ is highly degenerate while $\mathrm{Ta}_{0.81} \mathrm{CoSb}$ is close to being a semiconductor. $^{59}$ There is some level of control that can be achieved, as demonstrated in $\mathrm{Nb}_{0.8+\delta} \mathrm{CoSb}$, which can be doped between $0.5-6.5 \times 10^{21} \mathrm{~cm}^{-3}$ by varying the nominal vacancy fraction. ${ }^{183}$ One complication to doping control is the dependence of $\delta$ on the annealing temperature. ${ }^{190}$

Relative to the $\mathrm{X}_{\mathrm{IV}} \mathrm{NiSn}$ materials, $m_{\mathrm{DoS}}^{*}$ for these materials is quite large, ranging from $10 m_{\mathrm{e}}$ for $\mathrm{V}_{0.87} \mathrm{CoSb}$ to $5.9 \mathrm{~m}_{\mathrm{e}}$ for $\mathrm{Ta}_{0.81} \mathrm{CoSb}$ (Table 1). ${ }^{59,183,191}$ The lower magnitude of $\mu_{\mathrm{H}}$ $\left(\sim 4 \mathrm{~cm}^{2} \mathrm{~V}^{-1} \mathrm{~s}^{-1}\right.$ for $\left.\mathrm{Nb}_{0.8+\delta} \mathrm{CoSb}\right)$ may point to an increase in $m_{\mathrm{b}}^{*}$, but calculated bandstructures for both $\mathrm{NbCoSb}$ and $\mathrm{Nb}_{0.8}$ CoSb suggests more bands can contribute than the singly degenerate $X$-point minimum that is commonly observed (Fig. 7). ${ }^{188}$ Assuming a doubly degenerate conduction band as shown in Table $1, m_{\mathrm{b}}^{*}$ for $\mathrm{Nb}_{0.8+\delta} \mathrm{CoSb}$ is calculated to be $\sim 2.33 m_{\mathrm{e}}$, which is a large value compared to $\mathrm{n}$-type $\mathrm{X}_{\mathrm{IV}} \mathrm{NiSn}$.
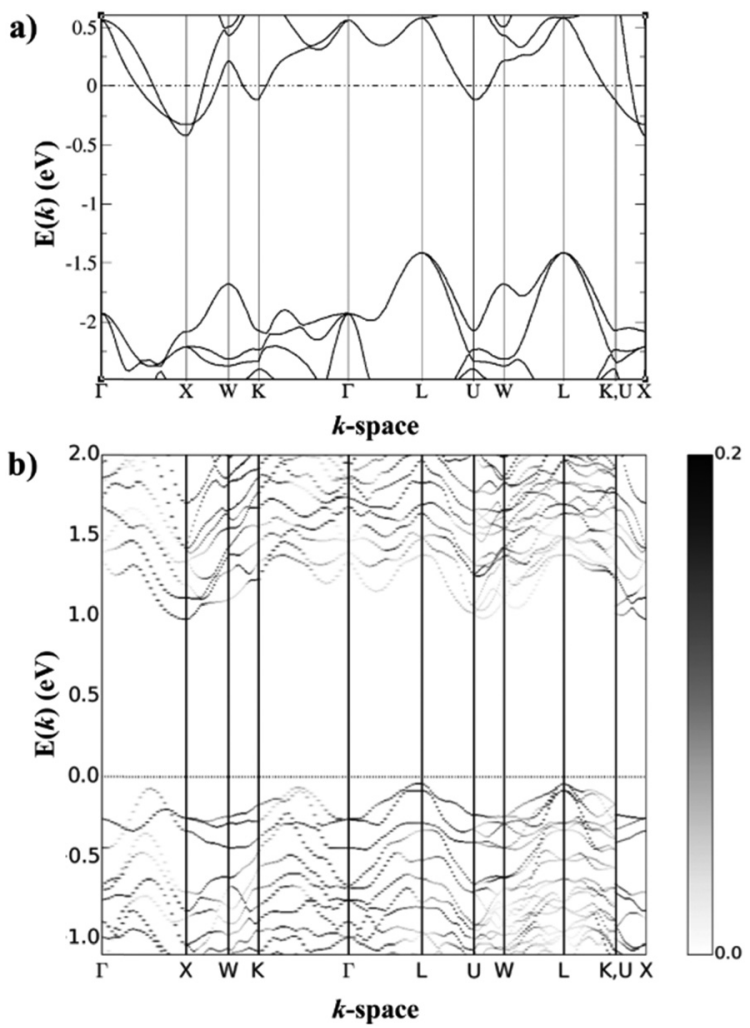

Fig. 7 Calculated electronic band structures of (a) 19 electron NbCoSb and (b) 18 electron $\mathrm{Nb}_{0.8} \mathrm{CoSb}$. NbCoSb is metallic, although the gap in the lower energy states is typical of semiconducting half-Heusler materials, with an $L$-point valence band maximum and an $X$-point conduction band minimum. $\mathrm{Nb}_{0.8} \mathrm{CoSb}$ contains these features but has additional conduction band states at the $U$-point, which could be responsible for the increased $m_{\text {Dos }}^{*}$ compared to NbCoSn. Reproduced from Zeier et al. 2017, Chemistry of Materials. ${ }^{188}$
One unusual behaviour in this family is the very low $\kappa_{1}$ in $\mathrm{V}_{0.87} \mathrm{CoSb}$ below $2 \mathrm{~W} \mathrm{~m}^{-1} \mathrm{~K}^{-1}$, which would expected to be larger than the $\mathrm{Nb}$ and $\mathrm{Ta}$ phases due its lower formula mass. ${ }^{59,191}$ The relative acoustic behaviour of the $\mathrm{V}_{0.8+\delta} \mathrm{CoSb}$ and $\mathrm{Nb}_{0.8+\delta} \mathrm{CoSb}$ materials have been confirmed to be similar, with no significant effect caused by vacancies observed through experiment, which would point to a reduced $\kappa_{\mathrm{l}}$, with measured $v_{\mathrm{s}}$ in the $\mathrm{Nb}_{0.8+\delta} \mathrm{CoSb}$ varying by no more than $\pm 2 \%$ between $0<\delta<0.2 .^{183,191}$ As of yet there is no clear explanation for this extremely low value. One can note that the experimental acoustic properties point to a large $\gamma$ for these materials (Table 2), which correlates with strong Umklapp scattering and low $\kappa_{1}$ as shown in Fig. 3. One structural feature of interest in these phases is the potential ordering of the $X_{V}$ site vacancies. ${ }^{192-195}$ Over large distances the vacancies are disordered, but at the nanoscale the vacancies are short-range ordered (SRO), offering a route to reduce $\kappa_{\mathrm{L}}{ }^{192}$ Furthermore, Monte Carlo simulated vacancy ordering coupled to DFT supercell calculations points to widening of the electronic CBM (increase in $m_{\mathrm{b}}^{*}$ ) relative to the ordered $\mathrm{Nb}_{0.8} \mathrm{CoSb}$ and the presence of Co-defect states in the band gap, with electron diffraction simulations confirming existence of SRO in real samples. ${ }^{195}$ A more detailed discussion on the vacancy ordering in these materials can be found in the 2021 review by Xia et al. ${ }^{12}$

The majority of reports on the $\mathrm{X}_{\mathrm{V} 0.8} \mathrm{CoSb}$ materials have utilised a similar synthetic protocol, with melted elemental pieces being optionally ball-milled and then consolidated by hot-pressing/ SPS. ${ }^{183,184}$ However, a powder route consisting of solid-state reaction and hot pressing achieves similar performance. ${ }^{59}$ Finally, a recent report on $\mathrm{V}_{0.855} \mathrm{Ti}_{0.1} \mathrm{CoSb}$ used a direct ball milling and consolidation approach and achieved $z T$ values larger than other reported $\mathrm{V}_{0.8+\delta} \mathrm{CoSb}$ samples. ${ }^{191}$ This suggests that for the group $\mathrm{V}$ based materials, these relatively straightforward powder based routes may be more feasible than for $\mathrm{X}_{\mathrm{IV}} \mathrm{NiSn}$, where the best performing samples are invariably prepared using melting routes.

\subsection{Other $\mathrm{HH}$ phases}

The best performing new and existing materials have been described above, but exploration of new phases has turned up some interesting results. One recent $\mathrm{HH}$ family which has emerged is the $\mathrm{X}_{\mathrm{V}} \operatorname{CoSn}\left(\mathrm{X}_{\mathrm{V}}=\mathrm{Nb}\right.$ and $\left.\mathrm{Ta}\right)$ phases, which are intrinsically n-type materials. ${ }^{187,196-198}$ The bandstructure of NbCoSn appears contain a doubly degenerate $X$-point conduction band minimum, giving $N_{\mathrm{v}}=6$, which appears to be partially responsible for $m_{\mathrm{DoS}}^{*}=6.1 m_{\mathrm{e}}$ in the $\mathrm{NbCoSn}_{1-x} \mathrm{Sb}_{x}$ series (Table 1). ${ }^{197,198}$ At present the largest $z T$ is found for $\mathrm{X}$-site alloying between $\mathrm{Nb}$ and $\mathrm{Ta}$, yielding $z T_{100 \mathrm{~K}}=0.75$ for $\mathrm{Nb}_{0.4} \mathrm{Ta}_{0.6} \mathrm{CoSn}_{0.94} \mathrm{Sb}_{0.06}{ }^{196}$ Better low temperature performance has been observed when using $\mathrm{Pt}$ as both n-type dopant and phonon scatterer in $\mathrm{NbCo}_{0.95} \mathrm{Pt}_{0.05} \mathrm{Sn}$, due to the large mass difference between Co and Pt. ${ }^{197}$ While it would be useful to use $\mathrm{V}$ for X-site alloying, the VCoSn phase does not appear to readily form. ${ }^{131}$ While there have been reports of the phase being observed by powder diffraction, the evidence presented is less than convincing. ${ }^{199,200}$ It has been suggested that this 
composition is difficult to reach through normal processing routes, but might be made through non-equilibrium processes. ${ }^{201}$ Finally, p-type doping has also been demonstrated using scandium doping in $\mathrm{Nb}_{1-x} \mathrm{Sc}_{x} \mathrm{CoSn}$, however these samples have relatively poor performance, with the largest $z T_{879 \mathrm{~K}}=$ 0.13 reported for $\mathrm{Nb}_{0.95} \mathrm{Sc}_{0.05} \mathrm{CoSn} .^{202}$

An established family of $\mathrm{HH}$ alloys that has recently gained renewed interest are the $\mathrm{RNiSb}$ phase $(\mathrm{R}=$ lanthanide, Sc). ${ }^{203-206}$ As synthesised, these materials are p-type and are characterised by spontaneous $\mathrm{Ni}$ deficiency (as much as $15 \%) .{ }^{207}$ They also have small band gaps $\left(E_{\mathrm{g}} \sim 0.3 \mathrm{eV}\right)$, leading to substantial bipolar transport at low temperatures, ultimately limiting the maximum achievable $z T$ values. A large study comparing $\mathrm{R}=\mathrm{Sc}$, Dy, Ho, Er, Tm and Lu, confirmed the intrinsic p-type behaviour with semiconductor like $S(T)$ and $\rho(T) .{ }^{205}$ Typical peak $S^{2} / \rho=1-1.5 \mathrm{~mW} \mathrm{~m}^{-1} \mathrm{~K}^{-2}$ for the RNiSb materials with highest reported $z T \sim 0.3$ at $650 \mathrm{~K}^{205,208,209}$ Careful analysis of the bipolar transport, suggested much higher electron than hole mobilities. ${ }^{204}$ Subsequent attempts at n-type doping exploiting Te in $\mathrm{ScNiSb}_{1-x} \mathrm{Te}_{x}$ yielded large $S^{2} / \rho=4 \mathrm{~mW} \mathrm{~m}^{-1} \mathrm{~K}^{-2}$, demonstrating the potential of n-type RNiSb systems. Substitution of Te is also correlated to an increasing $m_{\mathrm{DoS}}^{*}$, providing another example of the significant impact of a doping element on the underlying bandstructure. ${ }^{206}$ No $z T$ values were reported, but the chemical flexibility for substitution on the $\mathrm{X}$ site and potential to manipulate the $\mathrm{Ni}$ deficiency (concentration and potentially SRO through heat treatment), suggest that these materials are promising for further exploration.

Another interesting development is the exploration of "double HH" phases, which combine an equal mixture of 17 electron and 19 electron $\mathrm{HH}$ phases. ${ }^{112}$ For example the model material proposed in 2019 was [TiFeSb $]_{0.5}[\text { TiNiSb }]_{0.5}$, each of which forms a HH-like phase independently. Experimental realisation of $[\text { TiFeSb }]_{1-x}[\text { TiNiSb }]_{x}$ was successful, showing that VEC $<18$ were p-type and VEC $>18$ were n-type as would be expected, and that isoelectronic alloying using $\mathrm{Hf}$ could be used to reduce $\kappa_{\mathrm{l}}{ }^{210}$ Some unusual points emerged, such as the large reduction in $\kappa_{1}$ just above and below $x=0.5$ and massive apparent $m_{\text {Dos }}^{*}$ values up to $23.8 m_{\mathrm{e}}$, which was later confirmed by a separate group. ${ }^{211}$ The emergence of defective $\mathrm{HH}$ phases and double- $\mathrm{HH}$ phases has provided an extended range of potential compositions to explore, which has allowed for the application of computational screening, beyond the common style of reporting the first principles properties of stoichiometric XYZ HHs. ${ }^{112,212}$ The emergence of these phases coincide with the development of effective band structure techniques, that allow supercell bandstructures to be compared to stoichiometric parent phases. ${ }^{213,214}$

\section{Recent developments in half-Heusler thermoelectric generators}

There has been an increased research effort in recent years aimed at implementing $\mathrm{HH}$ materials into TEG modules and systems. ${ }^{215-219}$ It is now more common for "materials" studies to include work on prototype devices, ${ }^{121,122,179}$ while an increasing number of manuscripts are dedicated to electrical and thermal contacting of $\mathrm{HH}$ materials. ${ }^{220-224}$ Most of this published work is from research institutions but there has been industrial work producing $\mathrm{HH}$ materials and generators, most notably from GMZ energy in the USA, and the Isabellen Hutte Heusler company and Vacuum Schmelzen in Germany. A vital aspect in translating materials to TEG performance is the electrical and thermal contacting. In particular, the requirements for electrical contacting are strict in order to maintain as much of the intrinsic performance of the $\mathrm{HH}$ materials. The effective $z T$ for a "contacted" material is given by: ${ }^{4}$

$$
z T_{\text {leg }}=\left[\frac{L}{L+2 \rho_{\mathrm{c}} \sigma}\right] z T_{\mathrm{avg}}
$$

This leads to strict criteria on permissible contact resistances, e.g. for a $L=2 \mathrm{~mm}$ height leg, $\rho_{\mathrm{c}}<5 \mu \Omega \mathrm{cm}^{2}$ to keep losses $<5-10 \%$. In addition to a low contact resistance, the contacts also need to be stable under operating conditions, i.e. no chemical reaction with the TE materials, often necessitating the use of barrier layers. ${ }^{4}$ In terms of reviewing the literature, comparison of published results on TEG modules is difficult as they depend on dimensions of the legs, measurement conditions, heat flow through the legs and minimising heat losses. An overview of reported power densities and efficiencies for a range of $\mathrm{HH}$ based TEG modules is given in Table 3.

Table 3 Reported power densities from half-Heusler TEG module fabrication studies. Where reported, the efficiencies are on the order of 5-10\%

\begin{tabular}{|c|c|c|c|c|c|}
\hline n-/p-type materials & $\begin{array}{l}\text { \# couples } \\
\left(\text { dimensions } \mathrm{mm}^{3}\right)\end{array}$ & $z T$ (n/p-type@ $T / \mathrm{K})$ & $\begin{array}{l}\text { Power density } \\
\left(\mathrm{W} \mathrm{cm}^{-2}\right) /(\Delta T / \mathrm{K})\end{array}$ & Efficiency (\%) & Ref. \\
\hline Large-scale melt $\mathrm{X}_{\mathrm{IV}} \mathrm{NiSn} / \mathrm{X}_{\mathrm{IV}} \mathrm{CoSb}$ & $7(2.5 \times 2.5 \times 3)$ & 0.8/0.5@773 K & $3.2(525 \mathrm{~K})$ & 5 & 215 \\
\hline Milled nano- $\mathrm{X}_{\mathrm{IV}} \mathrm{NiSn} / \mathrm{X}_{\mathrm{IV}} \mathrm{CoSb}$ & $\begin{array}{l}1(1.8 \times 1.8 \times 2) \\
28(1 \text { module }) \\
400 \text { modules }\end{array}$ & 1.0/0.9@773 K/973 K & $\begin{array}{l}5.3(500 \mathrm{~K}) \\
4.0(500 \mathrm{~K}) \\
2.8(500 \mathrm{~K})\end{array}$ & $\frac{7}{2.1}$ & 216 and 241 \\
\hline Self-propagating $\mathrm{X}_{\mathrm{IV}} \mathrm{NiSn} / \mathrm{X}_{\mathrm{IV}} \mathrm{CoSb}$ & 8 & 1.0/0.9@773/973 K & $\begin{array}{l}2.4(680 \mathrm{~K})^{a b} \\
1.7(680 \mathrm{~K})\end{array}$ & $\begin{array}{l}8 \\
9.5\end{array}$ & 217 \\
\hline $\mathrm{X}_{\mathrm{IV}} \mathrm{NiSn} / \mathrm{X}_{\mathrm{V}} \mathrm{FeSb}$ & 8 & 1.0/1.0@973/1200 K & $2.1(655 \mathrm{~K})^{a}$ & 8.3 & 218 \\
\hline $\mathrm{X}_{\mathrm{IV}} \mathrm{NiSn} / \mathrm{X}_{\mathrm{V}} \mathrm{FeSb}$ & 1 & 1.0/1.0@773/973 K & $6.2(500 \mathrm{~K})$ & - & 122 \\
\hline $\mathrm{X}_{\mathrm{IV}} \mathrm{NiSn} / \mathrm{X}_{\mathrm{V}} \mathrm{FeSb}$ & $1(1.5 \times 1.5 \times 2.4)$ & 1.0/1.0@773/973 K & $8.6(570 \mathrm{~K})$ & 6.2 & 224 \\
\hline $\mathrm{TiNiSn} / \mathrm{X}_{\mathrm{V}} \mathrm{FeSb}$ & $18(1.75 \times 1.75 \times 4.0)$ & 0.4/0.4@873 K & $3.1(575 \mathrm{~K})$ & - & 219 \\
\hline
\end{tabular}

${ }^{a}$ Surface area of module, not TE material. ${ }^{b}$ This study covers a range of leg lengths and surface areas, showing the inverse correlation between efficiency and power density. 
One of the first papers to address upscaling and device manufacture originated from the Fraunhofer Institute in $2014 .{ }^{215}$ This work used vacuum melting and casting to prepare kilogram scale ingots of optimal n-type $\mathrm{Zr}_{0.4} \mathrm{Hf}_{0.6} \mathrm{NiSn}_{0.98} \mathrm{Sb}_{0.02}$ and p-type $\mathrm{Zr}_{0.5} \mathrm{Hf}_{0.5} \mathrm{NiSb}_{0.8} \mathrm{Sn}_{0.2}$. The $\mathrm{HH}$ materials had $z T \sim 0.8$ (n-type) and $\sim 0.5$ (p-type) at $773 \mathrm{~K}$, respectively. TEG modules containing $7 \mathrm{n} / \mathrm{p}$-couples were fabricated using $\mathrm{Cu}$ contacts and a brazing process. These were exposed to repeated thermal cycling up to $873 \mathrm{~K}$ and thermal shock without degradation of performance. The power density was $3.2 \mathrm{~W} \mathrm{~cm}^{-2}$ (area of thermoelectric) from a $527 \mathrm{~K}$ gradient, with the cold side near room temperature. The efficiency was estimated to be $\sim 5 \%$ with an average TEG module $Z T \sim 0.4$.

Zhang et al. demonstrated a $1 \mathrm{~kW}$ TEG for use in automotive applications. ${ }^{216}$ The $\mathrm{HH}$ materials used were based on milled nanostructured $\mathrm{X}_{\mathrm{IV}} \mathrm{NiSn}$ and $\mathrm{X}_{\mathrm{IV}} \mathrm{CoSb}$ with $z T=1(773 \mathrm{~K})$ and $z T$ $=0.9(973 \mathrm{~K})$, respectively. The production process and different stages in the TEG module development are illustrated in Fig. 8. $\mathrm{A} \mathrm{Ag-Cu} \mathrm{brazing} \mathrm{alloy} \mathrm{was} \mathrm{used} \mathrm{to} \mathrm{bond} \mathrm{the} \mathrm{legs} \mathrm{directly} \mathrm{to} \mathrm{the}$ $\mathrm{Cu}$ leads through heating in vacuum at $825{ }^{\circ} \mathrm{C}$. Unicouple generators produced $5.3 \mathrm{~W} \mathrm{~cm} \mathrm{~cm}^{-2}$ (500 K gradient), while a module consisting of 28 couples generated $4 \mathrm{~W} \mathrm{~cm}{ }^{-2}(500 \mathrm{~K}$ gradient). The reduced power density of the module is caused by parasitic losses, attributed to thermal losses between the inert atmosphere steel encapsulation and TEG device (Fig. 8). The final TEG that was embedded in the exhaust stream of a heavy-duty vehicle used an impressive number of 400 TEG modules and could generate $1 \mathrm{~kW}$ electrical output (power density $\sim 2.8 \mathrm{~W} \mathrm{~cm}^{-2}$ ) with a $2.1 \%$ heat-to-electricity efficiency ( $340 \mathrm{~K}$ gradient, with an average $823 \mathrm{~K}$ exhaust temperature).

Reflecting the development of the new p-type compositions, a shift has occurred towards $\mathrm{X}_{\mathrm{V}} \mathrm{FeSb}$ as the counterpart to $\mathrm{X}_{\mathrm{IV}} \mathrm{NiSn}$. The initial materials development study by $\mathrm{Fu}$ et al. reported a power density $\sim 2 \mathrm{~W} \mathrm{~cm}^{-2}$ from an 8 couple TEG module (650 K gradient). ${ }^{121}$ A subsequent study geared towards improving the device performance yielded a measured $2.1 \mathrm{~W} \mathrm{~cm}-2$ power density and $8.3 \%$ efficiency from a $655 \mathrm{~K}$ gradient. $^{218}$ Simulations as part of this work suggest a maximum efficiency of $10.5 \%$ is possible, but this would only be possible at with a reduction of power density. The work reporting ultrahigh $300 \mathrm{~K}$

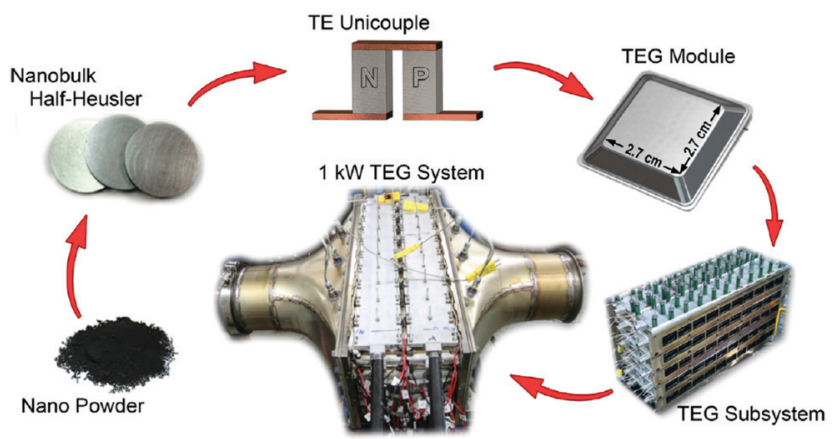

Fig. 8 Schematic illustrating upscaling of half-Heusler materials production, electrical contacting, TEG module and incorporation of TEG subsystem into exhaust stream of a heavy vehicle. Reproduced from Zhang et al. 2015, Energy Conversion and Management. ${ }^{216}$ power factors in NbFeSb translates to a very large TEG power density $\sim 20 \mathrm{~W} \mathrm{~cm}^{-2}$ (500 K gradient), albeit measured on a single contacted bar of material (and not in a TEG geometry). ${ }^{99}$ TaFeSb shows similar high power densities based on measurement of a single leg. ${ }^{47}$ Further work on NbFeSb in a unicouple device using a high-performance $\mathrm{X}_{\mathrm{IV}} \mathrm{NiSn}$ composition as the n-type, enables a device power density of $6.2 \mathrm{~W} \mathrm{~cm}^{-2}$ (500 K gradient), outperforming a comparable unicouple device with a $\mathrm{X}_{\mathrm{IV}} \mathrm{CoSb}$ p-type leg $\left(5.5 \mathrm{~W} \mathrm{~cm}^{-2}\right) .{ }^{122}$ Furthermore, the $\mathrm{NbFeSb}$ material used in that study did not contain $\mathrm{Hf}$ and is hence only about $1 / 6$ of the cost of the alternative $\mathrm{X}_{\mathrm{IV}} \mathrm{CoSb}$ p-types (typical $30-70 \% \mathrm{Hf}$ on the $\mathrm{X}$-site), offering a significant cost saving. Subsequent improvements in device contacting and geometry enabled a power density $8.6 \mathrm{~W} \mathrm{~cm}^{-2}$ at $6 \%$ efficiency under a $570 \mathrm{~K}_{\text {gradient. }}{ }^{224}$ This is a clear demonstration that the outstanding performance of $\mathrm{NbFeSb}$ can be translated to working TEG devices.

Self-propagating synthesis is a promising route to produce large quantities of materials that has recently been applied to $\mathrm{HH}$ materials. ${ }^{67,68}$ Using this processing, 200 gram batches of $\mathrm{Zr}_{0.5} \mathrm{Hf}_{0.5} \mathrm{NiSn}_{0.985} \mathrm{Sb}_{0.015}$ and $\mathrm{Zr}_{0.5} \mathrm{Hf}_{0.5} \mathrm{CoSb}_{0.8} \mathrm{Sn}_{0.2}$ were prepared and consolidated using conventional hot pressing. ${ }^{217}$ These were then fabricated into TEG modules containing 8 unicouple pairs. This study covered a range of leg geometries, where the ratio of leg height over area $(L / A)$ can be used to favour either efficiency (increase $L / A$ ) or power density (decrease $L / A)$. Limiting measured values in a $680 \mathrm{~K}$ gradient are $\sim 2.4 \mathrm{~W} \quad \mathrm{~cm}^{-2} \quad(\sim 8 \%$ efficiency $)$ and $\sim 1.7 \quad \mathrm{~W} \quad \mathrm{~cm}^{-2}$ (9.5\% efficiency). Simulations suggest an upper limit of $\sim 3.1 \mathrm{~W} \mathrm{~cm}^{-2}$ and $10.5 \%$ for the power density and efficiency, respectively. ${ }^{217}$ However, it is worth noting that the performance of these modules is limited by relatively large contact resistances, $\sim 30 \mu \Omega \mathrm{cm}^{-2}$ for both $\mathrm{n}$ - and p-type legs. A final noteworthy study focused on TiNiSn (hence avoiding the use of $\mathrm{Hf}$ ) as the n-type material and NbFeSb as the p-type. Despite a low $z T_{873 \mathrm{~K}} \sim 0.4$ for both $\mathrm{n}$ - and p-types, a fabricated TEG with 16 pairs showed a respectable power density of $\sim 3.1 \mathrm{~W} \mathrm{~cm}^{-2}$ from a $575 \mathrm{~K}$ gradient, reflecting the large $S^{2} \sigma$ of the HHs. ${ }^{219}$

\section{Conclusions}

Significant progress has been made in the development of $\mathrm{HH}$ thermoelectrics with the emergence of new high-performing $\mathrm{p}$ type materials based on $\mathrm{X}_{\mathrm{V}} \mathrm{FeSb}$ and $\mathrm{ZrCoBi}$, and further development of existing n-types based on $\mathrm{X}_{\mathrm{IV}} \mathrm{NiSn}$. Application of these materials in TEG modules has led to the demonstration of promising power outputs and efficiencies. Looking ahead there are a number of areas that deserve attention. Further work on translating materials into TEGs is needed, including underpinning work on electrical and thermal contacting and stability studies. A related area is the development of scalable synthetic routes to mass produce $\mathrm{HH}$ alloys with good performance. These more applied activities should be underpinned by further materials development work as there continues to be significant potential for further improvements. One area of interest is the elimination of parasitic effects, for example grain 
boundary resistances, enabling the intrinsic materials performance to be extracted. Another area is new design concepts, in particular building on the much-improved understanding of the electronic structure, ${ }^{225-227}$ and the emergence of new classes of more complex $\mathrm{HH}$ alloy compositions. ${ }^{112}$ The complex $\mathrm{HH}$ alloys behave opposite to the conventional XYZ compositions: they have low thermal conductivities but also relatively poor power factors. Uniting large power factors and low thermal conductivities remains the key challenge in $\mathrm{HH}$ materials development. The largely harmonic bonding limits the strength of phonon-phonon scattering, leaving structural disorder as the most plausible route to achieve low $\kappa_{1}$. A possible interesting route is to focus on grain boundary engineered composite samples, where the boundary region is exploited to suppress phonon transmission and reduce $\kappa_{\mathrm{l}}$. This has been demonstrated for graphene decorated skutterudites and titanium oxides, ${ }^{228,229}$ whilst dislocation networks have been exploited in $\mathrm{Bi}_{2} \mathrm{Te}_{3} \cdot{ }^{230}$ In principle, these approaches can be applied to $\mathrm{HH}$ alloys, and the key challenge is to find appropriate additives and processing routes to manipulate the microstructure. In terms of homogenous materials, advances might come from the design of materials with favourable bandstructures, enabling large power factors at lower doping levels, hence limiting the electronic thermal conductivity. ${ }^{227}$ One possible route to enhance $S$ without affecting $\sigma$ is the introduction of resonant states, leading to a "spike" in the electronic density of states. This concept has been explored for $\mathrm{X}_{\mathrm{IV}} \mathrm{NiSn}$ with some evidence of a favourable impact on the power factor and thermoelectric performance. ${ }^{231,232}$ As already remarked, the similar conduction band structures for $\mathrm{XYZ} \mathrm{HH}$ compositions limits opportunities for band engineering in the ntypes. In the p-types, there is more diversity and hence more opportunity for bandstructure engineering. ZrCoBi and $\mathrm{NbFeSb}$ are both systems that naturally benefit from large valley and orbital degeneracies. Alloying has been widely explored to reduce the lattice thermal conductivity but can also lead to substantially different bandstructures. Recent work using unfolded supercell calculations has shown that new bands can emerge in substituted HH compositions (e.g. in vacancy systems, ${ }^{170}$ for interstitials ${ }^{58}$ and complex compositions ${ }^{233}$ ) and this is another possible route for performance improvements. This is an area where theory could lead experiments by identifying new compositions with promising electronic bandstructures.

To conclude, great progress has been made over the past decade, driven by improvements in materials preparation and through better understanding from first principles and semiempirical modelling. Many avenues of research remain open for exploration in the future and some of these will undoubtedly lead to better materials performance. The current generation of materials is already good enough for niche applications in thermoelectric waste heat recovery. Improved performance, or increased penalties for carbon emissions, may lead to increased industrial interest for large scale application in thermoelectric power generation.

\section{Author contributions}

RJQ undertook the data analysis based on the literature and drafted figures and tables. JWGB supervised the work and acquired funding. Both authors contributed to writing the article.

\section{Conflicts of interest}

There are no conflicts of interest to declare.

\section{Appendix A - supplemental equations}

DFT computational papers will typically report the bulk $(B)$ and shear $(G)$ moduli, from elastic tensors $\left(C_{i j}\right)$. The crystallographic density $(\rho)$ is simply obtained following a sufficiently converged geometry optimisation of the unit cell. The longitudinal $\left(v_{1}\right)$ and transverse $\left(v_{t}\right)$ can be expressed as: $:^{243,244}$

$$
\begin{gathered}
v_{\mathrm{l}}=\left(\frac{3 B+4 G}{3 \rho}\right)^{\frac{1}{2}} \\
v_{\mathrm{t}}=\left(\frac{G}{\rho}\right)^{\frac{1}{2}}
\end{gathered}
$$

Experimentally, most reports on the acoustic properties by thermoelectric groups report both $v_{1}$ and $v_{\mathrm{t}}$ alongside the average velocity of sound $\left(v_{\mathrm{s}}\right)$. The subscripts used to denote the sound velocities can vary between reports (the most common issue being transverse versus shear velocity of sound). Calculation of $v_{\mathrm{s}}$ is typically achieved using the following expression: ${ }^{244}$

$$
v_{\mathrm{s}}=\left[\frac{1}{3}\left(\frac{1}{v_{\mathrm{l}}{ }^{3}}+\frac{2}{v_{\mathrm{t}}{ }^{3}}\right)\right]^{-\frac{1}{3}}
$$

Although alternative averaging equations are sometimes used. ${ }^{245}$ This equation is biased heavily towards the longitudinal contribution. The Debye temperature $\left(\theta_{\mathrm{D}}\right)$ can be calculated using the above values: ${ }^{246}$

$$
\theta_{\mathrm{D}}=\frac{\hbar}{k_{\mathrm{B}}}\left(\frac{6 \pi^{2}}{V_{0}}\right) v_{\mathrm{s}}
$$

where $V_{0}$ is the volume per atom. This equation can be found in a number of different forms, expressing $V_{0}$ in terms of the number of atoms, using Plancks constant and moving around the $2 \pi$ factor, or even moving $v_{\mathrm{s}}$ inside of the brackets. The final elastic property required to estimate Umklapp scattering is the Gruneisen anharmonicity parameter $(\gamma)$, which quantifies bond anharmonicity. Different $\gamma$ can be found in the literature, but given the information we have available the acoustic $\gamma$ is used, calculated using the equivalent expressions: ${ }^{113,245}$

$$
\begin{gathered}
\gamma=\frac{9\left(v_{\mathrm{l}}^{2}-\frac{4}{3} v_{\mathrm{t}}^{2}\right)}{2\left(v_{\mathrm{l}}^{3}+v_{\mathrm{t}}^{2}\right)} \text { or } \gamma=\frac{3}{2}\left(\frac{1+\nu}{2-3 \nu}\right) \\
\text { where } \nu=\frac{1-2\left(\frac{v_{\mathrm{t}}}{v_{\mathrm{l}}}\right)^{2}}{2-2\left(\frac{v_{\mathrm{t}}}{v_{\mathrm{l}}}\right)^{2}}
\end{gathered}
$$


where $\nu$ is the Poisson ratio. A more involved procedure to determine $\gamma$ uses the phonon bandstructure to calculate $\gamma(\boldsymbol{q})$, which can be done through DFT. ${ }^{247}$

Within the SPB model, $\mathrm{HH}$ materials are typically treated with acoustic phonon scattering as the dominant carrier scattering mechanism. For clarity, the SPB model uses the following equations with only acoustic phonon scattering: ${ }^{91,248}$

$$
\begin{aligned}
& F_{i}(\eta)=\int_{0}^{\infty} \frac{\varepsilon^{i}}{1+\exp [\varepsilon-\eta]} \mathrm{d} \varepsilon \\
& S=\frac{k_{\mathrm{B}}}{e}\left(\frac{2 F_{1}}{F_{0}}-\eta\right) \\
& n_{\mathrm{H}}=\frac{8 \pi}{3}\left(\frac{2 m_{\mathrm{DoS}}^{*} k_{\mathrm{B}} T}{h^{2}}\right)^{\frac{3}{2}} \frac{2 F_{0}^{2}}{F_{-0.5}} \\
& \mu_{\mathrm{H}}^{\mathrm{ac}}=\frac{\pi e \hbar^{4}}{\sqrt{2}\left(k_{\mathrm{B}} T\right)^{\frac{3}{2}}} \frac{\nu_{\mathrm{L}}^{2} d}{E_{\mathrm{def}^{2}}{ }^{2}} \frac{1}{m_{\mathrm{b}}^{* 3 / 2} m_{\mathrm{I}}^{*}} \frac{F_{-0.5}}{2 F_{0}} \\
& \mu_{\mathrm{H}}^{\mathrm{al}}=\frac{8 e \hbar^{4}}{3 \sqrt{2}\left(k_{\mathrm{B}} T\right)^{\frac{1}{2}}} \frac{N_{0}}{E_{\mathrm{al}}{ }^{2} x(1-x)} \frac{1}{m_{\mathrm{b}}^{* 3 / 2} m_{\mathrm{I}}^{*}} \frac{F_{-0.5}}{2 F_{0}}
\end{aligned}
$$

where $\eta$ is the reduced Fermi energy, $n_{\mathrm{H}}$ and $\mu_{\mathrm{H}}$ are the Hall concentration and Hall mobility determined directly from Hall measurements. $\eta$ is typically solved numerically from $S . m_{\text {DoS }}^{*}$ is typically determined from a series of samples at fixed temperature by plotting $S$ vs. $n_{\mathrm{H}}$ in a Pisarenko plot and fitting for a fixed $m_{\mathrm{DoS}}^{*}$, although a single datapoint can be used. The weighted mobility $\left(\mu_{\mathrm{w}}\right)$ is a measure of the fundamental mobility of a material independent of $n_{\mathrm{H}}$ and can be defined as: ${ }^{248,249}$

$$
\mu_{\mathrm{w}}=\mu_{0}\left(\frac{m_{\mathrm{DoS}}^{*}}{m_{\mathrm{e}}}\right)^{\frac{3}{2}} \propto \frac{N_{\mathrm{v}}}{m_{\mathrm{b}}^{*}} .
$$

where $\mu_{0}$ is the $n_{\mathrm{H}}=0$ limit within the SPB model. From this relationship, multiple highly dispersive bands are preferable to a single low dispersion band with the same $m_{\text {Dos }}^{*}$. A relationship compatible with $S(T)$ and $\sigma(T)$ is expressed as: ${ }^{249}$

$$
\mu_{\mathrm{w}}=\frac{3 h^{3} \sigma}{8 \pi e\left(2 m_{\mathrm{e}} k_{\mathrm{B}} T\right)^{\frac{3}{2}}}\left[\frac{\mathrm{e}^{\left[\frac{|S|}{k_{\mathrm{B}} / e}-2\right]}}{1+\mathrm{e}^{\left[-5\left(\frac{|S|}{k_{\mathrm{B}} / e}-1\right)\right]}}+\frac{\frac{3}{\pi^{2}} \frac{|S|}{k_{\mathrm{B}} / e}}{\left.1+\mathrm{e}^{\left[5\left(\frac{|S|}{k_{\mathrm{B}} / e}-1\right)\right]}\right]}\right]
$$

\section{Acknowledgements}

The EPSRC (EP/N01717X/1) and Leverhulme Trust (RPG-2020177) for funding and Heriot-Watt University is for a James Watt Scholarship for RJQ.

\section{References}

1 W. Gong, M. Yadav and A. J. Jacobson, MRS Online Proc. Libr., 2009, 1126, 807.
2 Thermoelectric Energy Conversion, ed. R. Funahashi, Woodhead Publishing, 2021.

3 Materials, preparation, and characterization in thermoelectrics, ed. D. M. Rowe, CRC Press, Boca Raton, 2012.

4 W. Liu, Q. Jie, H. S. Kim and Z. Ren, Acta Mater., 2015, 87, 357-376.

5 D. Champier, Energy Convers. Manage., 2017, 140, 167-181.

6 X.-L. Shi, J. Zou and Z.-G. Chen, Chem. Rev., 2020, 120, $7399-7515$.

7 T. J. Zhu, Y. T. Liu, C. G. Fu, J. P. Heremans, J. G. Snyder and X. B. Zhao, Adv. Mater., 2017, 29, 1605884.

8 G. J. Snyder and E. S. Toberer, Nat. Mater., 2008, 7, 105-114.

9 M. W. Gaultois, T. D. Sparks, C. K. H. Borg, R. Seshadri, W. D. Bonificio and D. R. Clarke, Chem. Mater., 2013, 25, 2911-2920.

10 S. K. Yee, S. LeBlanc, K. E. Goodson and C. Dames, Energy Environ. Sci., 2013, 6, 2561-2571.

$11 \mathrm{~J} . \mathrm{-W}$. G. Bos, in Thermoelectric Energy Conversion, ed. R. Funahashi, Woodhead Publishing, 2021, pp. 125-142.

12 K. Xia, C. Hu, C. Fu, X. Zhao and T. Zhu, Appl. Phys. Lett., 2021, 118, 140503.

13 S. Chen and Z. Ren, Mater. Today, 2013, 16, 387-395.

14 J. W. G. Bos and R. A. Downie, J. Phys.: Condens. Matter, 2014, 26, 433201.

15 T. Zhu, C. Fu, H. Xie, Y. Liu and X. Zhao, Adv. Energy Mater., 2015, 5, 1500588.

16 S. J. Poon, J. Phys. D: Appl. Phys., 2019, 52, 493001.

17 B. A. Cook, G. P. Meisner, J. Yang and C. Uher, International Conference on Thermoelectrics, ICT, Proceedings, IEEE, 1999, pp. 64-67.

18 C. Uher, J. Yang, S. Hu, D. T. Morelli and G. P. Meisner, Phys. Rev. B: Condens. Matter Mater. Phys., 1999, 59, 8615-8621.

19 Y. Xia, S. Bhattacharya, V. Ponnambalam, A. L. Pope, S. J. Poon and T. M. Tritt, J. Appl. Phys., 2000, 88, 1952-1955.

20 J. Toboła and J. Pierre, J. Alloys Compd., 2000, 296, 243-252.

21 S. Bhattacharya, A. L. Pope, R. T. Littleton IV, T. M. Tritt, V. Ponnambalam, Y. Xia and S. J. Poon, Appl. Phys. Lett., 2000, 77, 2476.

22 Y. Xia, V. Ponnambalam, S. Bhattacharya, A. L. Pope, S. J. Poon and T. M. Tritt, J. Phys.: Condens. Matter, 2001, 13, 77-89.

23 S. R. Culp, J. W. Simonson, S. J. Poon, V. Ponnambalam, J. Edwards and T. M. Tritt, Appl. Phys. Lett., 2008, 93, 022105.

24 S. Ogut and K. M. Rabe, Phys. Rev. B: Condens. Matter Mater. Phys., 1995, 51, 10443-10453.

25 H. Hohl, A. P. Ramirez, C. Goldmann, G. Ernst, B. Wölfing and E. Bucher, J. Phys.: Condens. Matter, 1999, 11, 1697-1709.

26 P. Larson, S. D. Mahanti, S. Sportouch and M. G. Kanatzidis, Phys. Rev. B: Condens. Matter Mater. Phys., 1999, 59, 15660-15668.

27 P. Larson, S. D. Mahanti and M. G. Kanatzidis, Phys. Rev. B: Condens. Matter Mater. Phys., 2000, 62, 12754-12762.

28 Q. Shen, L. Chen, T. Goto, T. Hirai, J. Yang, G. P. Meisner and C. Uher, Appl. Phys. Lett., 2001, 79, 4165-4167.

29 Y. Kawaharada, K. Kurosaki, H. Muta, M. Uno and S. Yamanaka, J. Alloys Compd., 2004, 377, 312-315. 
30 Y. Pei, H. Wang and G. J. Snyder, Adv. Mater., 2012, 24, 6125-6135.

31 H. J. Goldsmid, Proc. Phys. Soc., London, Sect. B, 1954, 67, 360-363.

32 R. P. Chasmar and R. Stratton, J. Electron. Control, 1959, 7, 52-72.

33 D. Narducci, Appl. Phys. Lett., 2011, 99, 102104.

34 D. Nemir and J. Beck, J. Electron. Mater., 2010, 39, 1897-1901.

35 W. Liu, H. S. Kim, Q. Jie and Z. Ren, Scr. Mater., 2016, 111, 3-9.

36 X. Yan, G. Joshi, W. Liu, Y. Lan, H. Wang, S. Lee, J. W. Simonson, S. J. Poon, T. M. Tritt, G. Chen and Z. F. Ren, Nano Lett., 2011, 11, 556-560.

37 G. Joshi, X. Yan, H. Z. Wang, W. S. Liu, G. Chen and Z. F. Ren, Adv. Energy Mater., 2011, 1, 643-647.

38 M. Schwall and B. Balke, Phys. Chem. Chem. Phys., 2013, 15, 1868-1872.

39 R. A. Downie, D. A. MacLaren and J. W. G. Bos, J. Mater. Chem. A, 2014, 2, 6107-6114.

40 S. Populoh, M. H. Aguirre, O. C. Brunko, K. Galazka, Y. Lu and A. Weidenkaff, Scr. Mater., 2012, 66, 1073-1076.

41 H. Hazama, M. Matsubara, R. Asahi and T. Takeuchi, J. Appl. Phys., 2011, 110, 063710.

42 J. P. A. Makongo, D. K. Misra, X. Y. Zhou, A. Pant, M. R. Shabetai, X. L. Su, C. Uher, K. L. Stokes and P. F. P. Poudeu, J. Am. Chem. Soc., 2011, 133, 18843-18852.

43 J. E. Douglas, C. S. Birkel, M. S. Miao, C. J. Torbet, G. D. Stucky, T. M. Pollock and R. Seshadri, Appl. Phys. Lett., 2012, 101, 183902.

44 Y. W. Chai and Y. Kimura, Acta Mater., 2013, 61, 6684-6697.

45 R. A. Downie, D. A. MacLaren, R. I. Smith and J. W. G. Bos, Chem. Commun., 2013, 49, 4184-4186.

46 W. Silpawilawan, S.-A. Tanuslip, Y. Ohishi, H. Muta and K. Kurosaki, Phys. Status Solidi A, 2020, 217, 2000419.

47 H. T. Zhu, J. Mao, Y. W. Li, J. F. Sun, Y. M. Wang, Q. Zhu, G. N. Li, Q. C. Song, J. W. Zhou, Y. H. Fu, R. He, T. Tong, Z. H. Liu, W. Y. Ren, L. You, Z. M. Wang, J. Luo, A. Sotnikov, J. M. Bao, K. Nielsch, G. Chen, D. J. Singh and Z. F. Ren, Nat. Commun., 2019, 10, 270.

48 H. Zhu, R. He, J. Mao, Q. Zhu, C. Li, J. Sun, W. Ren, Y. Wang, Z. Liu, Z. Tang, A. Sotnikov, Z. Wang, D. Broido, D. J. Singh, G. Chen, K. Nielsch and Z. Ren, Nat. Commun., 2018, 9, 1-9.

49 T. Graf, C. Felser and S. S. P. Parkin, Prog. Solid State Chem., 2011, 39, 1-50.

50 W. G. Zeier, J. Schmitt, G. Hautier, U. Aydemir, Z. M. Gibbs, C. Felser and G. J. Snyder, Nat. Rev. Mater., 2016, 1, 16032.

51 S. Anand, K. Xia, V. I. Hegde, U. Aydemir, V. Kocevski, T. Zhu, C. Wolverton and G. J. Snyder, Energy Environ. Sci., 2018, 11, 1480-1488.

52 K. Tolborg and B. B. Iversen, Chem. Mater., 2021, 33, 5308-5316.

53 A. Page, C. Uher, P. F. Poudeu and A. Van Der Ven, Phys. Rev. B: Condens. Matter Mater. Phys., 2015, 92, 174102.
54 K. Kirievsky, Y. Gelbstein and D. Fuks, J. Solid State Chem., 2013, 203, 247-254.

55 D. T. Do, S. D. Mahanti and J. J. Pulikkoti, J. Phys.: Condens. Matter, 2014, 26, 275501.

56 Y. G. G. Yu, X. W. Zhang and A. Zunger, Phys. Rev. B, 2017, 95, 085201.

57 R. A. Downie, S. A. Barczak, R. I. Smith and J. W. G. Bos, J. Mater. Chem. C, 2015, 3, 10534-10542.

58 D. A. Ferluccio, B. F. Kennedy, S. A. Barczak, S. R. Popuri, C. Murray, M. Pollet and J. W. G. Bos, J. Phys.: Energy, 2021, 3, 035001.

59 D. A. Ferluccio, J. E. Halpin, K. L. Macintosh, R. J. Quinn, E. Don, R. I. Smith, D. A. Maclaren and J. W. G. Bos, J. Mater. Chem. C, 2019, 7, 6539-6547.

60 M. Biesuz, T. Saunders, D. Ke, M. J. Reece, C. Hu and S. Grasso, J. Mater. Sci. Technol., 2021, 69, 239-272.

61 J. Yu, C. Fu, Y. Liu, K. Xia, U. Aydemir, T. C. Chasapis, G. J. Snyder, X. Zhao and T. Zhu, Adv. Energy Mater., 2018, 8, 1701313.

62 T. Nagase, K. Mizuuchi and T. Nakano, Entropy, 2019, 21, 483. 63 S. A. Barczak, J. E. Halpin, J. Buckman, R. Decourt, M. Pollet, R. I. Smith, D. A. MacLaren and J.-W. G. Bos, ACS Appl. Mater. Interfaces, 2018, 10, 4786-4793.

64 S. A. Barczak, R. J. Quinn, J. E. Halpin, K. Domosud, R. I. Smith, A. R. Baker, E. Don, I. Forbes, K. Refson, D. A. MacLaren and J. W. G. Bos, J. Mater. Chem. A, 2019, 7, 27124-27134.

65 C. S. Birkel, W. G. Zeier, J. E. Douglas, B. R. Lettiere, C. E. Mills, G. Seward, A. Birkel, M. L. Snedaker, Y. Zhang, G. J. Snyder, T. M. Pollock, R. Seshadri and G. D. Stucky, Chem. Mater., 2012, 24, 28.

66 T. Hu, W. Cao, D. Yang, Y. Yan, Y. Cao, T. Zhang, X. Su, W. Liu, P. Poudeu-Poudeu and X. Tang, Scr. Mater., 2019, 165, 140-144.

67 X. Su, F. Fu, Y. Yan, G. Zheng, T. Liang, Q. Zhang, X. Cheng, D. Yang, H. Chi, X. Tang, Q. Zhang and C. Uher, Nat. Commun., 2014, 5, 4908.

68 Y. Xing, R. Liu, Y.-Y. Sun, F. Chen, K. Zhao, T. Zhu, S. Bai and L. Chen, J. Mater. Chem. A, 2018, 6, 19470-19478.

69 T. Hu, D. Yang, X. Su, Y. Yan, Y. You, W. Liu, C. Uher and X. Tang, ACS Appl. Mater. Interfaces, 2018, 10, 864-872.

70 N. S. Chauhan, S. Bathula, B. Gahtori, S. D. Mahanti, A. Bhattacharya, A. Vishwakarma, R. Bhardwaj, V. N. Singh and A. Dhar, ACS Appl. Mater. Interfaces, 2019, 11, 47830-47836.

71 W. Ren, H. Zhu, J. Mao, L. You, S. Song, T. Tong, J. Bao, J. Luo, Z. Wang and Z. Ren, Adv. Electron. Mater., 2019, 5, 1900166.

72 Y. W. Chai, T. Oniki and Y. Kimura, Acta Mater., 2015, 85, 290-300.

73 S. V. Pedersen, J. R. Croteau, N. Kempf, Y. Zhang, D. P. Butt and B. J. Jaques, J. Solid State Chem., 2020, 285, 121203.

74 A. Novitskii, I. Serhiienko, A. Nepapushev, A. Ivanova, T. Sviridova, D. Moskovskikh, A. Voronin, H. Miki and V. Khovaylo, Intermetallics, 2021, 133, 107195.

75 E. Rausch, B. Balke, J. M. Stahlhofen, S. Ouardi, U. Burkhardt and C. Felser, J. Mater. Chem. C, 2015, 3, 10409-10414. 
76 E. Rausch, B. Balke, S. Ouardi and C. Felser, Phys. Chem. Chem. Phys., 2014, 16, 25258-25262.

77 Z. A. Munir and M. Ohyanagi, J. Mater. Sci., 2021, 56, 1-15.

78 K. Chen, C. Nuttall, E. Stefanaki, K. Placha, R. Tuley, K. Simpson, J. W. G. Bos and M. J. Reece, Scr. Mater., 2021, 191, 71-75.

79 A. D. LaLonde, T. Ikeda and G. J. Snyder, Rev. Sci. Instrum., 2011, 82, 025104.

$80 \mathrm{M}$. Yu, S. Grasso, R. Mckinnon, T. Saunders and M. J. Reece, Advances in Applied Ceramics, Taylor and Francis Ltd, 2017, vol. 116, pp. 24-60.

81 F. Gucci, T. G. Saunders, B. Srinivasan, F. Cheviré, D. A. Ferluccio, J. W. G. Bos and M. J. Reece, J. Alloys Compd., 2020, 837, 155058.

82 C. Chlique, G. Delaizir, O. Merdrignac-Conanec, C. Roucau, M. Dollé, P. Rozier, V. Bouquet and X. H. Zhang, Opt. Mater., 2011, 33, 706-712.

83 X. Wei, C. Back, O. Izhvanov, C. Haines and E. Olevsky, Materials, 2016, 9, 577.

84 R. Yamanoglu, I. Daoud and E. A. Olevsky, Powder Metall., 2018, 61, 178-186.

85 M. T. Dylla, A. Dunn, S. Anand, A. Jain and G. J. Snyder, Research, 2020, 2020, 1-8.

86 H. Zhu, J. Mao, Z. Feng, J. Sun, Q. Zhu, Z. Liu, D. J. Singh, Y. Wang and Z. Ren, Sci. Adv., 2019, 5, eaav5813.

87 Q. Ren, C. Fu, Q. Qiu, S. Dai, Z. Liu, T. Masuda, S. Asai, M. Hagihala, S. Lee, S. Torri, T. Kamiyama, L. He, X. Tong, C. Felser, D. J. Singh, T. Zhu, J. Yang and J. Ma, Nat. Commun., 2020, 11, 1-9.

88 S. S. Li, in Semiconductor Physical Electronics, ed. S. S. Li, Springer, New York, 2006, pp. 211-245.

89 J. W. Harrison and J. R. Hauser, Phys. Rev. B: Solid State, 1976, 13, 5347-5350.

90 H. Wang, A. D. LaLonde, Y. Pei and G. J. Snyder, Adv. Funct. Mater., 2013, 23, 1586-1596.

91 H. Xie, H. Wang, Y. Pei, C. Fu, X. Liu, G. J. Snyder, X. Zhao and T. Zhu, Adv. Funct. Mater., 2013, 23, 5123-5130.

92 C. Hu, K. Xia, X. Chen, X. Zhao and T. Zhu, Mater. Today Phys., 2018, 7, 69-76.

93 Y. Liu, C. Fu, K. Xia, J. Yu, X. Zhao, H. Pan, C. Felser and T. Zhu, Adv. Mater., 2018, 30, 1800881.

94 J. W. Zhou, H. T. Zhu, T. H. Liu, Q. C. Song, R. He, J. Mao, Z. H. Liu, W. Y. Ren, B. L. Liao, D. J. Singh, Z. F. Ren and G. Chen, Nat. Commun., 2018, 9, 1721.

95 J. Y. W. Seto, J. Appl. Phys., 1975, 46, 5247-5254.

96 J. J. Kuo, S. D. Kang, K. Imasato, H. Tamaki, S. Ohno, T. Kanno and G. J. Snyder, Energy Environ. Sci., 2018, 11, 429-434.

97 J. Y. Cao, D. Ekren, Y. D. Peng, F. Azough, I. A. Kinloch and R. Freer, ACS Appl. Mater. Interfaces, 2021, 13, 11879-11890.

98 S. R. Popuri, R. Decourt, J. A. McNulty, M. Pollet, A. D. Fortes, F. D. Morrison, M. S. Senn and J. W. G. Bos, J. Phys. Chem. C, 2019, 123, 5198-5208.

99 R. He, D. Kraemer, J. Mao, L. Zeng, Q. Jie, Y. C. Lan, C. H. Li, J. Shuai, H. S. Kim, Y. Liu, D. Broido, C. W. Chu, G. Chen and Z. Ren, Proc. Natl. Acad. Sci. U. S. A., 2016, 113, 13576-13581.
100 Q. Qiu, Y. Liu, K. Xia, T. Fang, J. Yu, X. Zhao and T. Zhu, Adv. Energy Mater., 2019, 9, 1803447.

101 C. Fu, M. Yao, X. Chen, L. Z. Maulana, X. Li, J. Yang, K. Imasato, F. Zhu, G. Li, G. Auffermann, U. Burkhardt, W. Schnelle, J. Zhou, T. Zhu, X. Zhao, M. Shi, M. Dressel, A. V. Pronin, G. J. Snyder and C. Felser, Adv. Sci., 2020, 7, 1902409.

102 L.-D. Zhao, S.-H. Lo, Y. Zhang, H. Sun, G. Tan, C. Uher, C. Wolverton, V. P. Dravid and M. G. Kanatzidis, Nature, 2014, 508, 373-377.

103 J. P. Heremans, V. Jovovic, E. S. Toberer, A. Saramat, K. Kurosaki, A. Charoenphakdee, S. Yamanaka and G. J. Snyder, Science, 2008, 321, 554-557.

104 A. Petersen, S. Bhattacharya, T. M. Tritt and S. J. Poon, J. Appl. Phys., 2015, 117, 035706.

105 J. Zou and A. Balandin, J. Appl. Phys., 2001, 89, 2932.

106 P. Hermet and P. Jund, J. Alloys Compd., 2016, 688, 248-252. 107 J. Shiomi, K. Esfarjani and G. Chen, Phys. Rev. B: Condens. Matter Mater. Phys., 2011, 84, 104302.

108 G. Ding, G. Y. Gao and K. L. Yao, J. Phys. D: Appl. Phys., 2015, 48, 235302.

109 A. Katre, J. Carrete and N. Mingo, J. Mater. Chem. A, 2016, 4, 15940-15944.

110 S. N. H. Eliassen, A. Katre, G. K. H. Madsen, C. Persson, O. M. Lovvik and K. Berland, Phys. Rev. B, 2017, 95, 045202.

111 M. Schrade, K. Berland, S. N. H. Eliassen, M. N. Guzik, C. Echevarria-Bonet, M. H. Sørby, P. Jenuš, B. C. Hauback, R. Tofan, A. E. Gunnæs, C. Persson, O. M. Løvvik and T. G. Finstad, Sci. Rep., 2017, 7, 13760.

112 S. Anand, M. Wood, Y. Xia, C. Wolverton and G. J. Snyder, Joule, 2019, 3, 1226-1238.

113 G. A. Naydenov, P. J. Hasnip, V. K. Lazarov and M. I. J. Probert, J. Phys.: Mater., 2019, 2, 035002.

114 R. He, T. Zhu, Y. Wang, U. Wolff, J.-C. Jaud, A. Sotnikov, P. Potapov, D. Wolf, P. Ying, M. Wood, Z. Liu, L. Feng, N. P. Rodriguez, G. J. Snyder, J. C. Grossman, K. Nielsch and G. Schierning, Energy Environ. Sci., 2020, 13, 5165-5176.

115 Thermal Conductivity: Theory, Properties and Applications, ed. T. M. Tritt, Kluwer Academic, New York, 2004.

116 J. Schmitt, Z. M. Gibbs, G. J. Snyder and C. Felser, Mater. Horiz., 2015, 2, 68-75.

117 H. S. Kim, W. Liu and Z. Ren, Energy Environ. Sci., 2017, 10, 69-85.

118 G. J. Snyder and A. H. Snyder, Energy Environ. Sci., 2017, 10, 2280-2283.

119 C. Fu, T. Zhu, Y. Pei, H. Xie, H. Wang, G. J. Snyder, Y. Liu, Y. Liu and X. Zhao, Adv. Energy Mater., 2014, 4, 1400600.

120 C. Fu, T. Zhu, Y. Liu, H. Xie and X. Zhao, Energy Environ. Sci., 2015, 8, 216-220.

121 C. G. Fu, S. Q. Bai, Y. T. Liu, Y. S. Tang, L. D. Chen, X. B. Zhao and T. J. Zhu, Nat. Commun., 2015, 6, 8144.

122 G. Joshi, R. He, M. Engber, G. Samsonidze, T. Pantha, E. Dahal, K. Dahal, J. Yang, Y. C. Lan, B. Kozinsky and Z. F. Ren, Energy Environ. Sci., 2014, 7, 4070-4076.

123 A. Tavassoli, F. Failamani, A. Grytsiv, G. Rogl, P. Heinrich, H. Müller, E. Bauer, M. Zehetbauer and P. Rogl, Acta Mater., 2017, 135, 263-276. 
124 H. Ma, C.-L. Yang, M.-S. Wang, X.-G. Ma and Y.-G. Yi, J. Phys. D: Appl. Phys., 2019, 52, 255501.

125 G. Surucu, M. Isik, A. Candan, X. Wang and H. H. Gullu, Phys. B, 2020, 587, 412146.

126 D. Zhao, M. Zuo, L. Bo and Y. Wang, Materials, 2018, 11, 728.

127 X. Yan, W. Liu, H. Wang, S. Chen, J. Shiomi, K. Esfarjani, H. Wang, D. Wang, G. Chen and Z. Ren, Energy Environ. Sci., 2012, 5, 7543-7548.

128 X. Yan, W. Liu, S. Chen, H. Wang, Q. Zhang, G. Chen and Z. Ren, Adv. Energy Mater., 2013, 3, 1195-1200.

129 E. Rausch, B. Balke, S. Ouardi and C. Felser, Energy Technol., 2015, 3, 1217-1224.

130 E. Rausch, M. V. Castegnaro, F. Bernardi, M. C. M. Alves, J. Morais and B. Balke, Acta Mater., 2016, 115, 308-313.

131 M. Asaad, J. Buckman, R. I. Smith and J. W. G. Bos, RSC $A d v .$, 2016, 6, 56511-56517.

132 O. Appel, S. Cohen, O. Beeri, N. Shamir, Y. Gelbstein and S. Zalkind, Materials, 2018, 11, 2296.

133 A. Berche and P. Jund, Intermetallics, 2018, 92, 62-71.

134 R. W. H. Webster, J. E. Halpin, S. R. Popuri, J. W. G. Bos and D. A. MacLaren, APL Mater., 2019, 7, 013206.

135 H. B. Kang, U. Saparamadu, A. Nozariasbmarz, W. J. Li, H. T. Zhu, B. Poudel and S. Priya, ACS Appl. Mater. Interfaces, 2020, 12, 36706-36714.

136 R. W. H. Webster, M. T. Scott, S. R. Popuri, J. W. G. Bos and D. A. MacLaren, Appl. Surf. Sci., 2020, 512, 145649.

137 K. Galazka, S. Populoh, L. Sagarna, L. Karvonen, W. J. Xie, A. Beni, P. Schmutz, J. Hulliger and A. Weidenkaff, Phys. Status Solidi A, 2014, 211, 1259-1266.

138 M. Asaad, J. Buckman and J. W. G. Bos, Metals, 2018, 8, 935.

139 M. Asaad, J. Buckman, R. I. Smith and J. W. G. Bos, J. Solid State Chem., 2019, 276, 181-189.

140 I. Ioannou, P. S. Ioannou, A. Delimitis, Y. Gelbstein, I. J. Giapintzakis and T. Kyratsi, J. Alloys Compd., 2021, 858, 158330.

141 T. Sekimoto, K. Kurosaki, H. Muta and S. Yamanaka, Mater. Trans., 2006, 47, 1445-1448.

142 R. He, H. Zhu, J. Sun, J. Mao, H. Reith, S. Chen, G. Schierning, K. Nielsch and Z. Ren, Mater. Today Phys., 2017, 1, 24-30.

143 R. F. Wang, S. Li, W. H. Xue, C. Chen, Y. M. Wang, X. J. Liu and Q. Zhang, Rare Met., 2021, 40, 40-47.

144 J. Pierre, R. V. Skolozdra, Y. K. Gorelenko and M. Kouacou, J. Magn. Magn. Mater., 1994, 134, 95-105.

145 J. Tobola, J. Pierre, S. Kaprzyk, R. V. Skolozdra and M. A. Kouacou, J. Phys.: Condens. Matter, 1998, 10, 1013-1032.

146 F. G. Aliev, N. B. Brandt, V. V. Moshchalkov, V. V. Kozyrkov, R. V. Skolozdra and A. I. Belogorokhov, Z. Phys. B: Condens. Matter, 1989, 75, 167-171.

147 F. G. Aliev, V. V. Kozyrkov, V. V. Moshchalkov, R. V. Scolozdra and K. Durczewski, Z. Phys. B: Condens. Matter, 1990, 80, 353-357.

148 S. Sakurada and N. Shutoh, Appl. Phys. Lett., 2005, 86, 1-3. 149 C. Yu, T.-J. Zhu, R.-Z. Shi, Y. Zhang, X.-B. Zhao and J. He, Acta Mater., 2009, 57, 2757-2764.
150 L. Chen, S. Gao, X. Zeng, A. Mehdizadeh Dehkordi, T. M. Tritt and S. J. Poon, Appl. Phys. Lett., 2015, 107, 041902.

151 R. A. Downie, R. I. Smith, D. A. MacLaren and J. W. G. Bos, Chem. Mater., 2015, 27, 2449-2459.

152 X. Li, P. Yang, Y. Wang, Z. Zhang, D. Qin, W. Xue, C. Chen, Y. Huang, X. Xie, X. Wang, M. Yang, C. Wang, F. Cao, J. Sui, X. Liu and Q. Zhang, Research, 2020, 2020, 1-9.

153 Y. W. Chai and Y. Kimura, Appl. Phys. Lett., 2012, 100, 033114.

154 C. S. Birkel, J. E. Douglas, B. R. Lettiere, G. Seward, N. Verma, Y. C. Zhang, T. M. Pollock, R. Seshadri and G. D. Stucky, Phys. Chem. Chem. Phys., 2013, 15, 6990-6997.

155 J. E. Douglas, C. S. Birkel, N. Verma, V. M. Miller, M. S. Miao, G. D. Stucky, T. M. Pollock and R. Seshadri, J. Appl. Phys., 2014, 115, 043720.

156 Y. F. Liu, P. Sahoo, J. P. A. Makongo, X. Y. Zhou, S. J. Kim, H. Chi, C. Uher, X. Q. Pan and P. F. P. Poudeu, J. Am. Chem. Soc., 2013, 135, 7486-7495.

157 J. P. A. Makongo, D. K. Misra, J. R. Salvador, N. J. Takas, G. Y. Wang, M. R. Shabetai, A. Pant, P. Paudel, C. Uher, K. L. Stokes and P. F. P. Poudeu, J. Solid State Chem., 2011, 184, 2948-2960.

158 J. E. Douglas, P. A. Chater, C. M. Brown, T. M. Pollock and R. Seshadri, J. Appl. Phys., 2014, 116, 163514.

159 E. E. Levin, F. Long, J. E. Douglas, M. L. C. Buffon, L. K. Lamontagne, T. M. Pollock and R. Seshadri, Materials, 2018, 11, 903.

160 S. A. Barczak, J. Buckman, R. I. Smith, A. R. Baker, E. Don, I. Forbes and J. W. G. Bos, Materials, 2018, 11, 536.

161 H. H. Xie, H. Wang, C. G. Fu, Y. T. Liu, G. J. Snyder, X. B. Zhao and T. J. Zhu, Sci. Rep., 2014, 4, 6888.

162 Y. T. Liu, H. H. Xie, C. G. Fu, G. J. Snyder, X. B. Zhao and T. J. Zhu, J. Mater. Chem. A, 2015, 3, 22716-22722.

163 K. S. Kim, Y. M. Kim, H. Mun, J. Kim, J. Park, A. Y. Borisevich, K. H. Lee and S. W. Kim, Adv. Mater., 2017, 29, 1702091.

164 H. J. Lee, K. H. Lee, L. Fu, G. Han, H. S. Kim, S. I. Kim, Y. M. Kim and S. W. Kim, Acta Mater., 2019, 180, 97-104.

165 M. N. Guzik, M. Schrade, R. Tofan, P. A. Carvalho, K. Berland, M. H. Sorby, C. Persson, A. E. Gunnaes and B. C. Hauback, CrystEngComm, 2019, 21, 3330-3342.

166 A. Berche and P. Jund, Materials, 2018, 11, 868.

167 Y. Kimura and Y. W. Chai, JOM, 2015, 67, 233-245.

168 A. Page, A. Van der Ven, P. F. P. Poudeu and C. Uher, J. Mater. Chem. A, 2016, 4, 13949-13956.

169 O. Appel and Y. Gelbstein, J. Electron. Mater., 2014, 43, 1976-1982.

170 M. Schwall and B. Balke, Materials, 2018, 11, 649.

171 M. N. Guzik, C. Echevarria-Bonet, M. D. Riktor, P. A. Carvalho, A. E. Gunnæs, M. H. Sørby and B. C. Hauback, Acta Mater., 2018, 148, 216-224.

172 G. Rogl, P. Sauerschnig, Z. Rykavets, V. V. Romaka, P. Heinrich, B. Hinterleitner, A. Grytsiv, E. Bauer and P. Rogl, Acta Mater., 2017, 131, 336-348.

173 M. Gürth, G. Rogl, V. V. Romaka, A. Grytsiv, E. Bauer and P. Rogl, Acta Mater., 2016, 104, 210-222. 
174 G. Rogl, K. Yubuta, V. V. Romaka, H. Michor, E. Schafler, A. Grytsiv, E. Bauer and P. Rogl, Acta Mater., 2019, 166, 466-483.

175 Y. Tang, X. Li, L. H. J. Martin, E. Cuervo Reyes, T. Ivas, C. Leinenbach, S. Anand, M. Peters, G. J. Snyder and C. Battaglia, Energy Environ. Sci., 2018, 11, 311-320.

176 M. Gurth, A. Grytsiv, J. Vrestal, V. V. Romaka, G. Giester, E. Bauer and P. Rogl, RSC Adv., 2015, 5, 92270-92291.

177 P. Sauerschnig, A. Grytsiv, J. Vrestal, V. V. Romaka, B. Smetana, G. Giester, E. Bauer and P. Rogl, J. Alloys Compd., 2018, 742, 1058-1082.

178 S. A. Barczak, PhD thesis, Heriot-Watt University, 2018.

179 H. B. Kang, B. Poudel, W. Li, H. Lee, U. Saparamadu, A. Nozariasbmarz, M. G. Kang, A. Gupta, J. J. Heremans and S. Priya, Mater. Today, 2020, 36, 63-72.

180 K. Sung Kim, Y.-M. Kim, H. Mun, J. Kim, J. Park, A. Y. Borisevich, K. Hyoung Lee, S. Wng Kim, K. S. Kim, Y.-M. Kim, H. Mun, S. W. Kim, J. Kim, J. Park, A. Y. Borisevich and K. H. Lee, Adv. Mater., 2017, 29, 1702091.

181 T. Zilber, S. Cohen, D. Fuks and Y. Gelbstein, J. Alloys Compd., 2019, 781, 1132-1138.

182 F. Aversano, A. Ferrario, S. Boldrini, C. Fanciulli, M. Baricco and A. Castellero, J. Mater. Eng. Perform., 2018, 27, 6306-6313.

183 K. Xia, Y. Liu, S. Anand, G. J. Snyder, J. Xin, J. Yu, X. Zhao and T. Zhu, Adv. Funct. Mater., 2018, 28, 1705845.

184 L. Huang, R. He, S. Chen, H. Zhang, K. Dahal, H. Zhou, H. Wang, Q. Zhang and Z. Ren, Mater. Res. Bull., 2015, 70, 773-778.

185 H. Zhang, Y. Wang, L. Huang, S. Chen, H. Dahal, D. Wang and Z. Ren, J. Alloys Compd., 2016, 654, 321-326.

186 L. H. Huang, Q. Y. Zhang, Y. M. Wang, R. He, J. Shuai, J. J. Zhang, C. Wang and Z. F. Ren, Phys. Chem. Chem. Phys., 2017, 19, 25683-25690.

187 D. A. Ferluccio, R. I. Smith, J. Buckman and J. W. G. Bos, Phys. Chem. Chem. Phys., 2018, 20, 3979-3987.

188 W. G. Zeier, S. Anand, L. Huang, R. He, H. Zhang, Z. Ren, C. Wolverton and G. J. Snyder, Chem. Mater., 2017, 29, 1210-1217.

189 K. Kaczmarska, J. Pierre, J. Beille, J. Tobola, R. V. Skolozdra and G. A. Melnik, J. Magn. Magn. Mater., 1998, 187, 210-220.

190 S. Anand, K. Xia, T. Zhu, C. Wolverton and G. J. Snyder, Adv. Energy Mater., 2018, 8, 1801409.

191 S. Li, F. Bai, R. Wang, C. Chen, X. Li, F. Cao, B. Yu, J. Sui, X. Liu, Z. Ren and Q. Zhang, Ann. Phys., 2020, 532, 1900440.

192 K. Y. Xia, P. F. Nan, S. H. Tan, Y. M. Wang, B. H. Ge, W. Q. Zhang, S. Anand, X. B. Zhao, G. J. Snyder and T. J. Zhu, Energy Environ. Sci., 2019, 12, 1568-1574.

193 P. Nan, K. Wu, Y. Liu, K. Xia, T. Zhu, F. Lin, J. He and B. Ge, Nanoscale, 2020, 12, 21624-21628.

194 N. Roth, T. J. Zhu and B. B. Iversen, IUCrJ, 2020, 7, 673-680.

195 S. Tan, P. Nan, K. Xia, H. Yang, T. Zhu, B. Ge and W. Zhang, J. Phys. Chem. C, 2021, 125, 1125-1133.
196 S. Li, H. Zhu, J. Mao, Z. Feng, X. Li, C. Chen, F. Cao, X. Liu, D. J. Singh, Z. Ren and Q. Zhang, ACS Appl. Mater. Interfaces, 2019, 11, 54.

197 F. Serrano-Sánchez, T. Luo, J. Yu, W. Xie, C. Le, G. Auffermann, A. Weidenkaff, T. Zhu, X. Zhao, J. A. Alonso, B. Gault, C. Felser and C. Fu, J. Mater. Chem. A, 2020, 8, 14822-14828.

198 R. He, L. Huang, Y. Wang, G. Samsonidze, B. Kozinsky, Q. Zhang and Z. Ren, APL Mater., 2016, 4, 104804.

199 C. S. Lue, Y. Oner, D. G. Naugle and J. H. Ross, IEEE Trans. Magn., 2001, 37, 2138-2140.

200 S. Hooshmand Zaferani, A. Darebaghi, S.-J. Hong, D. Vashaee and R. Ghomashchi, Energies, 2020, 13, 1459.

201 H. Shi, W. Ming, D. S. Parker, M. H. Du and D. J. Singh, Phys. Rev. B, 2017, 95, 195207.

202 R. Yan, W. Xie, B. Balke, G. Chen and A. Weidenkaff, Sci. Technol. Adv. Mater., 2020, 21, 122-130.

203 I. Wolańska, K. Synoradzki, K. Ciesielski, K. Załęski, P. Skokowski and D. Kaczorowski, Mater. Chem. Phys., 2019, 227, 29-35.

204 K. Ciesielski, K. Synoradzki, I. Veremchuk, P. Skokowski, D. Szymański, Y. Grin and D. Kaczorowski, Phys. Rev. Appl., 2020, 14, 054046.

205 K. Ciesielski, K. Synoradzki, I. Wolańska, P. Stachowiak, L. Kepiński, A. Jeżowski, T. Toliński and D. Kaczorowski, J. Alloys Compd., 2020, 816, 152596.

206 K. Ciesielski, I. Wolańska, K. Synoradzki, D. Szymański and D. Kaczorowski, Phys. Rev. Appl., 2021, 15, 044047.

207 T. Harmening, H. Eckert and R. Pöttgen, Solid State Sci., 2009, 11, 900-906.

208 K. Kawano, K. Kurosaki, T. Sekimoto, H. Muta and S. Yamanaka, Appl. Phys. Lett., 2007, 91, 062115.

209 K. Kawano, K. Kurosaki, H. Muta and S. Yamanaka, J. Appl. Phys., 2008, 104, 013714.

210 Z. Liu, S. Guo, Y. Wu, J. Mao, Q. Zhu, H. Zhu, Y. Pei, J. Sui, Y. Zhang and Z. Ren, Adv. Funct. Mater., 2019, 29, 1905044.

211 Q. Wang, X. Li, C. Chen, W. Xue, X. Xie, F. Cao, J. Sui, Y. Wang, X. Liu and Q. Zhang, Phys. Status Solidi A, 2020, 217, 2000096.

212 S. Guo, Z. Liu, Z. Feng, T. Jia, S. Anand, G. J. Snyder and Y. Zhang, J. Mater. Chem. A, 2020, 8, 23590-23598.

213 V. Popescu and A. Zunger, Phys. Rev. Lett., 2010, 104, 236403.

214 V. Popescu and A. Zunger, Phys. Rev. B: Condens. Matter Mater. Phys., 2012, 85, 085201.

215 K. Bartholomé, B. Balke, D. Zuckermann, M. Köhne, M. Müller, K. Tarantik and J. König, J. Electron. Mater., 2014, 43, 1775-1781.

216 Y. L. Zhang, M. Cleary, X. W. Wang, N. Kempf, L. Schoensee, J. Yang, G. Joshi and L. Meda, Energy Convers. Manage., 2015, 105, 946-950.

217 Y. F. Xing, R. H. Liu, J. C. Liao, Q. H. Zhang, X. G. Xia, C. Wang, H. Huang, J. Chu, M. Gu, T. J. Zhu, C. X. Zhu, F. F. Xu, D. X. Yao, Y. P. Zeng, S. Q. Bai, C. Uher and L. D. Chen, Energy Environ. Sci., 2019, 12, 3390-3399.

218 J. J. Yu, Y. F. Xing, C. L. Hu, Z. J. Huang, Q. Y. Qiu, C. Wang, K. Y. Xia, Z. Y. Wang, S. Q. Bai, X. B. Zhao, L. D. Chen and T. J. Zhu, Adv. Energy Mater., 2020, 10, 2000888. 
219 D. Landmann, Y. L. Tang, B. Kunz, R. Huber, D. Widner, P. Rickhaus, R. N. Widmer, H. R. Elsener and C. Battaglia, J. Appl. Phys., 2019, 126, 085113.

220 J. J. Shen, Z. Y. Wang, J. Chu, S. Q. Bai, X. B. Zhao, L. D. Chen and T. J. Zhu, ACS Appl. Mater. Interfaces, 2019, 11, 14182-14190.

221 Z. J. Huang, L. Yin, C. L. Hu, J. J. Shen, T. J. Zhu, Q. Zhang, K. Y. Xia, J. Z. Xin and X. B. Zhao, J. Mater. Sci. Technol., 2020, 40, 113-118.

222 Z. Y. Wang, C. G. Fu, K. Y. Xia, F. Liu, X. B. Zhao and T. J. Zhu, ACS Appl. Mater. Interfaces, 2021, 13, 7317-7323.

223 A. Nozariasbmarz, U. Saparamadu, W. J. Li, H. B. Kang, C. Dettor, H. T. Zhu, B. Poudel and S. Priya, J. Power Sources, 2021, 493, 229695.

224 D. Black, L. Schoensee, J. Richardson, T. Vleisides, N. Kempf, D. Z. Wang, Z. F. Ren and Y. L. Zhang, ACS Appl. Energy Mater., 2018, 1, 5986-5992.

225 P. Graziosi, C. Kumarasinghe and N. Neophytou, J. Appl. Phys., 2019, 126, 155701.

226 C. Kumarasinghe and N. Neophytou, Phys. Rev. B, 2019, 99, 195202.

227 P. Graziosi and N. Neophytou, J. Phys. Chem. C, 2020, 124, 18462-18473.

228 P. A. Zong, R. Hanus, M. Dylla, Y. S. Tang, J. C. Liao, Q. H. Zhang, G. J. Snyder and L. D. Chen, Energy Environ. Sci., 2017, 10, 183-191.

229 Y. Lin, M. T. Dylla, J. J. Kuo, J. P. Male, I. A. Kinloch, R. Freer and G. J. Snyder, Adv. Funct. Mater., 2020, 30, 1910079.

230 S. I. Kim, K. H. Lee, H. A. Mun, H. S. Kim, S. W. Hwang, J. W. Roh, D. J. Yang, W. H. Shin, X. S. Li, Y. H. Lee, G. J. Snyder and S. W. Kim, Science, 2015, 348, 109-114.

231 J. W. Simonson, D. Wu, W. J. Xie, T. M. Tritt and S. J. Poon, Phys. Rev. B: Condens. Matter Mater. Phys., 2011, 83, 235211.

232 L. Chen, Y. Liu, J. He, T. M. Tritt and S. J. Poon, AIP Adv., 2017, 7, 065208.
233 S. Guo, Z. Liu, Z. Feng, T. Jia, S. Anand, G. J. Snyder and Y. Zhang, J. Mater. Chem. A, 2020, 8, 23590-23598.

234 H. Joshi, D. P. Rai, A. Laref and R. K. Thapa, Mater. Res. Express, 2019, 6, 066307.

235 M. Zahedifar and P. Kratzer, Phys. Rev. B, 2018, 97, 035204.

236 B. Kong, B. Zhu, Y. Cheng, L. Zhang, Q. X. Zeng and X. W. Sun, Phys. B, 2011, 406, 3003-3010.

237 H. Muta, T. Yamaguchi, K. Kurosaki and S. Yamanaka, International Conference on Thermoelectrics, ICT, Proceedings, 2005, vol. 2005, pp. 339-342.

238 G. Rogl, A. Grytsiv, M. Gürth, A. Tavassoli, C. Ebner, A. Wünschek, S. Puchegger, V. Soprunyuk, W. Schranz, E. Bauer, H. Müller, M. Zehetbauer and P. Rogl, Acta Mater., 2016, 107, 178-195.

239 A. Jain, S. P. Ong, G. Hautier, W. Chen, W. D. Richards, S. Dacek, S. Cholia, D. Gunter, D. Skinner, G. Ceder and K. A. Persson, APL Mater., 2013, 1, 011002.

240 M. De Jong, W. Chen, T. Angsten, A. Jain, R. Notestine, A. Gamst, M. Sluiter, C. K. Ande, S. Van Der Zwaag, J. J. Plata, C. Toher, S. Curtarolo, G. Ceder, K. A. Persson and M. Asta, Sci. Data, 2015, 2, 1-13.

241 G. Joshi and B. Poudel, J. Electron. Mater., 2016, 45, 6047-6051.

242 R. J. Quinn, PhD thesis, Heriot-Watt University, 2021.

243 L. Kinsler, Fundamentals of Acoustics, Wiley, Hoboken, NJ, 4th edn, 2000.

244 M. Razeghi, Fundamentals of Solid State Engineering, Springer, New York, NY, 3rd edn, 2009.

245 V. N. Belomestnykh, Tech. Phys. Lett., 2004, 30, 91-93.

246 Q. Chen and B. Sundman, Acta Mater., 2001, 49, 947-961.

247 D. S. Kim, H. L. Smith, J. L. Niedziela, C. W. Li, D. L. Abernathy and B. Fultz, Phys. Rev. B: Condens. Matter Mater. Phys., 2015, 91, 14307.

248 A. F. May and G. J. Snyder, in Materials, Preparation, and Characterization in Thermoelectrics, ed. D. M. Rowe, 2012, pp. K1-K18.

249 G. J. Snyder, A. H. Snyder, M. Wood, R. Gurunathan, B. H. Snyder and C. Niu, Adv. Mater., 2020, 32, 2001537. 